\title{
Gas Release During Saltwell Pumping: Interpretation of Operational Data
}

\author{
J. L. Huckaby \\ L. M. Peurrung \\ P. A. Gauglitz
}

September 1999

Prepared for

the U.S. Department of Energy

under Contract DE-AC06-76RLO 1830

Pacific Northwest National Laboratory

Richland, Washington 99352 



\section{DISCLAIMER}

This report was prepared as an account of work sponsored by an agency of the United States Government. Neither the United States Government nor any agency thereof, nor any of their employees, make any warranty, express or implied, or assumes any legal liability or responsibility for the accuracy, completeness, or usefuiness of any information, apparatus, product, or process disclosed, or represents that its use would not infringe privately owned rights. Reference herein to any specific commercial product, process, or service by trade name, trademark, manufacturer, or otherwise does not necessarily constitute or imply its endorsement, recommendation, or favoring by the United States Government or any agency thereof. The views and opinions of authors expressed herein do not necessarily state or reflect those of the United States Government or any agency thereof. 


\section{DISCLAIMER}

Portions of this document may be illegible in electronic image products. Images are produced from the best available original document. 


\section{Summary}

The Hanford Site has 149 single-shell tanks (SSTs) containing radioactive waste that is a complex mix of radioactive and chemical products. To minimize the amount of material that could potentially leak into the surrounding soil, all of the SSTs are scheduled to have drainable liquid removed and to be designated as interim stabilized. While process equipment exists for removing drainable liquid, and its operation is well known from previous pumping campaigns, a number of safety issues associated with the release and potential ignition of flammable gases within the tanks needs to be addressed. The safety concerns associated with flammable gases stem from the observation that some of the waste in the SSTs generate and retain hazardous amounts of flammable gases, including hydrogen, nitrous oxide, and ammonia. Saltwell pumping to remove the interstitial liquid from SSTs is expected to cause the release of much of the retained gas, both insoluble (principally hydrogen) and soluble (principally ammonia), posing a number of safety concerns.

The purpose of this study, performed for the Project Hanford Management Contract Team as part of the Pacific Northwest National Laboratory ${ }^{(2)}$ Flammable Gas Project, is to evaluate the flammable gas release data taken during actual pumping operations. These data include headspace concentration data and, in the case of tank S-106, the headspace breathing rate measured using a tracer gas method. The goal of the study is to understand and explain the observed gas release behavior for any tank. The development of a sufficient understanding will help resolve the associated safety issues both during pumping operations and afterwards, during storage of waste.

On March 18, 1999, saltwell pumping commenced on tank S-102, the first passively ventilated SST with significant retained gas to be saltwell pumped. Pumping of tanks S-106 and S-103 also began in FY1999. Two of these tanks, S-102 and S-106, were equipped with the appropriate instrumentation to measure flammable gas concentrations in the headspace and other ancillary equipment areas. As expected, flammable gas levels in these two tanks rose when pumping began. Flammable gas data are also available for tanks SX-104 and SX-106, two actively vented SSTs. Saltwell pumping on these two tanks began in 1998.

The operational data show that in the passively vented tanks (S-106 and S-102), pumping elevates flammable gas concentrations in the headspace. To date, these concentrations have not approached lower flammability limits. Actively ventilated tanks (such as SX-104 and SX-106) have not shown significantly elevated hydrogen concentrations. This is not surprising given the dilution introduced by ventilation air, the low sensitivity of the instrumentation used, and, in the case of SX-104, the small amount of flammable gas in the waste.

(a) Pacific Northwest National Laboratory is operated by Battelle for the U.S. Department of Energy under Contract DE-AC06-76RLO 1830. 
The apparent rate of gas release from both tanks S-106 and S-102 are lower than expected based on our current physical model of the waste. In tank S-106, where pumping is nearly complete, hydrogen and nitrous oxide are exhibiting a slow, prolonged release behavior that suggests that their diffusion out of the waste is hindered by mass transfer limitations. It is postulated that waste heterogeneities may be acting as barriers to diffusion by creating undrained regions in the waste.

Because gas release is slowed, turning off the pump does not cause the release rate to fall quickly, as previously expected. Moreover, due to the slowness of the release, it is not clear yet whether pumping ultimately will release all of the retained gas in tank S-106.

The ammonia release in tank S-106 is prolonged, which is expected. Disagreement between the magnitude of the observed release with the predicted release may be due to the presence of a region depleted in ammonia near the waste surface which absorbs ammonia released from below. If so, ammonia release rates should eventually be more in line with predictions.

Only hydrogen data are available for tank S-102, and pumping is only $10-20 \%$ complete. The hydrogen release rate is again much lower than predicted for homogeneous waste. In this case, however, the gas that is released dissipates promptly in a manner consistent with unhindered gas phase diffusion through homogeneous waste. A potential explanation for the discrepancy between the observed and predicted release volumes is that previous releases of gas have reduced the gas stored near the surface of the waste. However, this theory is at odds with measurements taken from retained gas samples in 1998. Further pumping will provide more insight. 


\section{Contents}

Summary ...............................................................................................................................

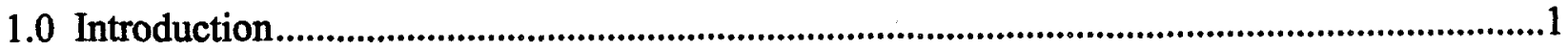

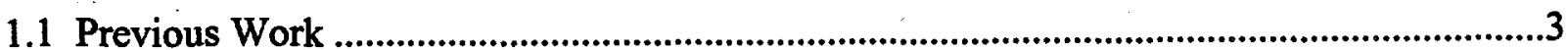

1.2 Mechanisms of Gas Release During Saltwell Pumping ….....................................................4

2.0 Modeling Approach ................................................................................................................

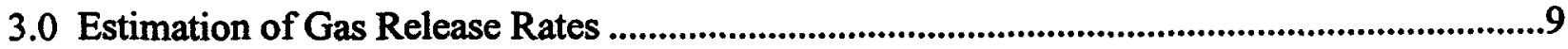

3.1 Method Description ....................................................................................................................9

3.2 Ventilation and Release Rate Calculations .............................................................................10

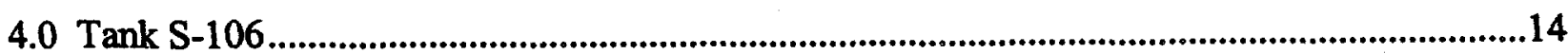

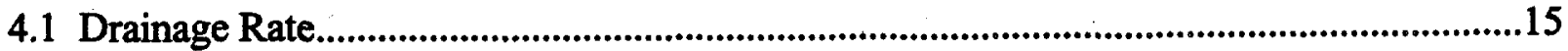

4.2 Hydrogen and Nitrous Oxide Release................................................................................17

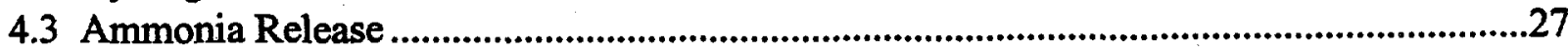

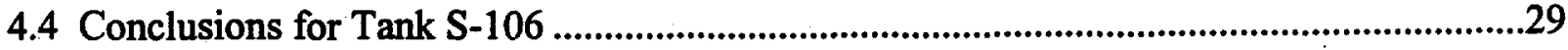

5.0 Tank S-102

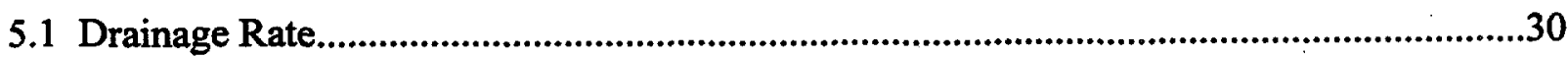

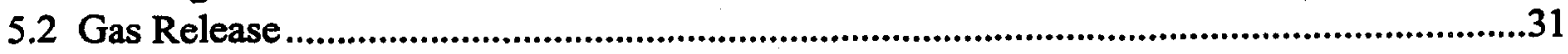

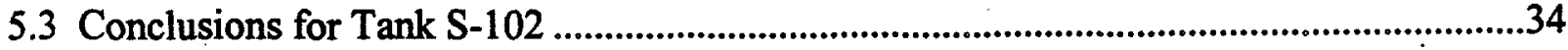

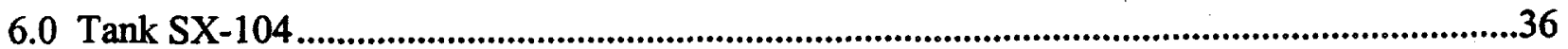

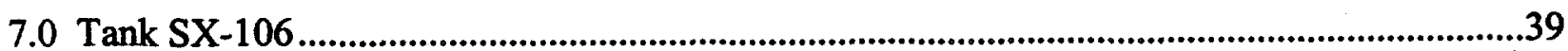

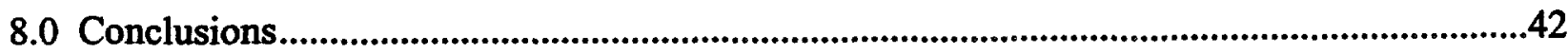

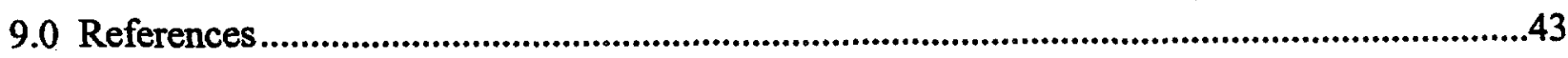




\section{Figures}

1.1 Saltwell Pumping and Movement of Dissolved Soluble Gas. Draining interstitial liquid by saltwell pumping causes invading air to expose retained bubbles and retained bubbles to expand as fluid head decreases. Dissolved soluble gas (small dots) diffuses and partitions into invading air; both gas species then diffuse into tank headspace against invading air.....

3.1 Tank S-106 Headspace Helium Tracer Gas Concentration and Logarithm of Concentration for Tracer Studies begun on April 15, 1999, and May 19, 1999.

4.1 Tank S-106 Observed Saltwell Liquid Level (measured as a pressure differential between dip tubes in the headspace and at the bottom of the saltwell), Calculated Saltwell Liquid Level, and Daily Average Waste Pumping Rate as Functions of Date. 15

4.2 Grid Pattern for STOMP Simulation of Tank S-106

4.3 Hydrogen, Nitrous Oxide, and Ammonia Concentrations in the Tank S-106 Headspace, with Daily Pumping Volumes as Functions of Date.

4.4 Tank S-106 Hydrogen Release Rate Calculated by STOMP (calculated), based on Measured Ventilation Rate and Concentration Data (observed), and Estimated from Average Ventilation Rate and Interpolated Concentration Data (estimated)

4.5 Tank S-106 Cumulative Released Hydrogen Volume Calculated by STOMP (calculated), based on Observed Ventilation Rate and Concentration Data (observed), and based on Average Ventilation Rate and Interpolated Concentration Data (estimated)

4.6 Tank S-106 Nitrous Oxide Release Rate Calculated by STOMP (calculated), based on Measured Ventilation Rate and Concentration Data (observed), and Estimated from Average Ventilation Rate and Interpolated Concentration Data (estimated)

4.7 Tank S-106 Cumulative Released Nitrous Oxide Volume Calculated by STOMP (calculated), based on Observed Ventilation Rate and Concentration Data (observed), and based on Average Ventilation Rate and Interpolated Concentration Data (estimated)

4.8 Comparison of Released Hydrogen Volumes for Tank S-106 Calculated by STOMP, by a Simple Draining Model, and Observed as Functions of Total Waste Pumped. 


\section{Figures (continued)}

4.9 Comparison of Observed and Estimated Hydrogen Release Data for Tank S-106 with that Calculated Using the Regular and Two Effective Diffusivities for Hydrogen.

4.10 Tank S-106 Ammonia Release Rate Calculated by STOMP (calculated), based on Measured Ventilation Rate and Concentration Data (observed), and Estimated from Average Ventilation Rate and Interpolated Concentration Data (estimated).

4.11 Tank S-106 Cumulative Released Ammonia Vapor Volume Calculated by STOMP (calculated), based on Observed Ventilation Rate and Concentration Data (observed), and based on Average Ventilation Rate and Interpolated Concentration Data (estimated)

5.1 Tank S-102 Observed Saltwell Liquid Level (measured as a pressure differential between dip tubes in the headspace and at the bottom of the saltwell), Calculated Saltwell Liquid Level, and Daily Average Waste Pumping Rate as Functions of Date.

5.2. Tank S-102 Headspace Hydrogen Concentration and Reported Daily Pumping Rates......32

5.3 Tank S-102 Observed and Calculated Headspace Hydrogen Concentrations

6.1 Tank SX-104 Headspace Hydrogen Concentration and Pumping Rate .37

6.2 Tank SX-104 Headspace Hydrogen Concentration and Pumping Rate with Expanded Scale on Primary Y-axis and with Hydrogen Concentration Averaged over Each Day .38

7.1 Tank SX-106 Headspace Hydrogen Concentration and Pumping Rate .40

7.2 Tank SX-106 Headspace Hydrogen Concentration and Pumping Rate with Expanded Scale on Primary Y-axis and with Hydrogen Concentration Averaged over Each Day 


\section{Tables}

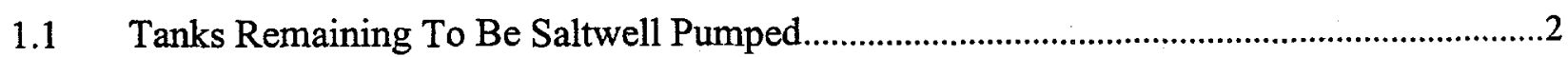

2.1 Values of Physical Parameters Used in the STOMP Simulations.......................................8

3.1 Tank S-106 One-Day Average Ventilation Rates ........................................................12

4.1 Comparison of Measured and Predicted Cumulative Gas Volumes Released ....................23

4.2 S-106 Gas Release Rates based on Measured Ventilation Rates and Headspace Concentrations. 


\subsection{Introduction}

The Hanford Site has 149 single-shell tanks (SSTs) containing radioactive waste that is a complex mix of radioactive and chemical products. Of these, 67 are known or suspected to have leaked liquid into the surrounding soil, while 82 are considered sound (Hanlon 1999). To minimize the amount of material that potentially could leak into the surrounding soil, all of the SSTs are scheduled to have drainable liquid removed and to be designated as interim stabilized..$^{(a)}$ Of the SSTs, 119 have been declared stabilized, and only 30 require further processing (Hanlon 1999). Many of the tanks have been declared stabilized administratively, with only 45 tanks having had drainable liquid removed. The pending consent decree between the Washington State Department of Ecology and the Office of River Protection.(U.S. District Court, Eastern District of Washington, 1999) sets a milestone to complete interim stabilization by September 2004. While process equipment exists for removing drainable liquid, and its operation is well known from previous pumping campaigns, a number of safety issues associated with the release and potential ignition of flammable gases within the tanks needs to be addressed.

The safety concerns associated with flammable gases stem from the observation that some of the waste in the SSTs generates and retains hazardous quantities of flammable gases, including hydrogen, nitrous oxide, and ammonia. Of the 30 SSTs remaining to be declared interim stabilized, 29 need to have drainable liquid removed by saltwell pumping (waste in tank 241-C-106 will be removed by sluicing), and 16 of these are on the Flammable Gas Watch List (FGWL) (Hopkins 1995; Hanlon 1999). Most of these tanks are in Facility Group 2 (Noorani 1997); that is, it is believed that tank operations may induce the release of significant quantities of flammable gas, but gas release does not occur spontaneously. In particular, saltwell pumping to remove the interstitial liquid from SSTs is expected to cause the release of much of the retained gas, both insoluble (principally hydrogen) and soluble (principally ammonia), posing a number of safety concerns (Peurrung et al. 1997; Meader 1996).

On March 18, 1999 saltwell pumping commenced on tank S-102, the first passively ventilated SST with significant retained gas. Pumping on tanks S-106 and S-103 also began in FY1999. Table 1.1 shows the current ${ }^{(b)}$ schedule for pumping these and the remaining tanks. Two of these tanks, S-102 and S-106, were equipped with the appropriate instrumentation to measure flammable gas concentrations in the headspace and other ancillary equipment areas. As expected, flammable gas levels in these two tanks rose when pumping began.

(a) While essentially all of the drainable liquid must be removed, specific criteria are used to determine when liquid removal is sufficiently thorough to allow the SSTs to be designated as interim stabilized (Hanlon 1999).

(b) As of July 20, 1999. 
Table 1.1 Tanks Remaining To Be Saltwell Pumped

\begin{tabular}{|c|c|c|c|c|c|c|c|}
\hline $\operatorname{Tank}^{(a)}$ & $\begin{array}{l}\text { Anticipated } \\
\text { Start Date }^{(b)}\end{array}$ & FGWL $^{(c)}$ & $\begin{array}{l}\text { Facility } \\
\text { Group }^{(\alpha)}\end{array}$ & $\begin{array}{l}\text { Void Fraction } \\
(\%)^{(e)}\end{array}$ & $\begin{array}{l}\text { Hydrogen } \\
(\% \text { LFL) })^{(t)}\end{array}$ & $\begin{array}{c}\text { Ammonia } \\
(\text { moles } / \mathrm{L})^{(\mathrm{s})}\end{array}$ & $\begin{array}{l}\text { Saltcake } \\
(\%)^{(h)}\end{array}$ \\
\hline SX-104 & Ongoing & yes & 3 & 0 & 10 & 0.1 & 78 \\
\hline $\mathrm{T}-104$ & Ongoing & - & 3 & & 0.14 & 0.07 & 0 \\
\hline $\mathrm{T}-110$ & Ongoing & yes & 2 & 0 & 32 & $5 \mathrm{E}-6$ & 0 \\
\hline SX-106 & Ongoing & yes & 2 & 9 & 78 & 0.09 & $\overline{86}$ \\
\hline S-102 & Ongoing & yes & 2 & 19 & 226 & 0.04 & 99 \\
\hline S-106 & Ongoing & - & 2 & 23 & 223 & 0.06 & 94 \\
\hline S-103 & Ongoing & - & 2 & 20 & 72 & 0.1 & 96 \\
\hline U-103 & $10 / 99$ & yes & 2 & 10 & 161 & 0.9 & 90 \\
\hline U-105 & $11 / 99$ & yes & 2 & 9 & 270 & 0.1 & 83 \\
\hline U-102 & $2 / 00$ & - & 3 & & 203 & 0.9 & 84 \\
\hline U-109 & $4 / 00$ & yes & 2 & 8 & 118 & 0.1 & 86 \\
\hline A-101 & $5 / 00$ & yes & 2 & & 379 & 0.05 & 100 \\
\hline SX-105 & $6 / 00$ & yes & 2 & & 87 & 0.1 & 89 \\
\hline$\overline{A X}-101$ & $8 / 00$ & yes & 3 & & 0.5 & 0.06 & 100 \\
\hline SX-103 & $10 / 00$ & yes & 2 & 18 & 216 & 0.09 & 82 \\
\hline SX-101 & $11 / 00$ & yes & 2 & 3 & 28 & 0.1 & 75 \\
\hline U-106 & $12 / 00$ & - & 2 & 3 & 37 & 0.1 & 82 \\
\hline BY-106 & $2 / 01$ & - & 2 & & 123 & 0.05 & $\overline{85}$ \\
\hline BY-105 & $4 / 01$ & - & 2 & & 144 & 0.09 & 69 \\
\hline U-108 & $5 / 01$ & yes & 2 & & 300 & 0.09 & 89 \\
\hline U-107 & $6 / 01$ & yes & 2 & 8 & 87 & 0.08 & 89 \\
\hline S-111 & $8 / 01$ & yes & 2 & 14 & 181 & 0.1 & 75 \\
\hline SX-102 & $8 / 01$ & yes & 2 & 12 & 93 & 0.1 & 78 \\
\hline $\mathrm{U}-111$ & $1 / 02$ & - & 2 & 0 & 97 & 0.07 & 92 \\
\hline S-109 & $3 / 02$ & - & 2 & & 145 & 0.07 & 98 \\
\hline S-112 & $4 / 02$ & yes & 2 & 0 & 30 & 0.08 & 99 \\
\hline S-101 & $6 / 04$ & - & 2 & 6 & 109 & 0.1 & 41 \\
\hline S-107 & $7 / 02$ & - & 2 & 4 & 138 & 0.1 & 19 \\
\hline C-103 & $8 / 02$ & - & 3 & & 2 & 0.030 & 0 \\
\hline \multicolumn{8}{|c|}{$\begin{array}{l}\text { (a) Full tank designations are } 241 \text { - followed by tank farm designation (e.g., BY; S, T) and tank number. Common usage } \\
\text { omits the } 241 \text {, using just the tank farm designation and tank number. } \\
\text { (b) Vladimiroff et al. (1999). } \\
\text { (c) Designated as on the FGWL (Hanlon 1999). } \\
\text { (d) From the BIO (Noorani 1997). } \\
\text { (e) Void fraction determined from estimates of retained gas volume and volume of wet solids. The retained gas is the 50th } \\
\text { percentile barometric pressure estimate from data reported in Hodgson et al. (1997) and supporting spreadsheets; we } \\
\text { included only those void fractions based on FIC or Enraf level data. } \\
\text { (f) Values represent the potential flammable gas concentrations in the tank headspaces (assuming all trapped gas was } \\
\text { released at once) as described by Hodgson et al. (1997), and the values given are the largest entries for each tank in } \\
\text { (g) Vable 2-1; many of these estimates have large uncertainties and are overestimates of retained gas. } \\
\text { (h) Fraction of solids classified as saltcake by Hanlon (1999). }\end{array}$} \\
\hline
\end{tabular}


The purpose of this study, performed for the Project Hanford Management Contract Team as part of the Pacific Northwest National Laboratory (PNNL) Flammable Gas Project, is to evaluate the flammable gas release data taken during actual pumping operations. Our tool in the evaluation is a model developed during FY 1996 and 1997 at PNNL (Peurrung et al. 1997, 1996). The goals of the evaluation are twofold. First, we seek to understand and explain the observed gas release behavior for any tank. The model helps us interpret release behavior by showing the importance of different physical mechanisms and waste properties that govern gas release. The development of a sufficient understanding will help resolve the associated safety issues both during pumping operations and afterwards, during storage of waste. Second, we seek to evaluate how well the model predicts actual tank behavior to determine if it can be used as a predictive tool to aid decision-making, e.g. whether to install a ventilation system before pumping a certain tank.

The remainder of this introduction summarizes previous work and describes the current conceptual understanding of how saltwell pumping releases gas retained in the waste. Section 2 presents the computational method, based on the conceptual model, used to predict release rates. Section 3 describes the methods used to measure flammable gas concentrations in the tank headspaces during pumping and the tracer gas method used to convert those concentrations to release rates and volumes. Each subsequent section then presents and discusses the results for one of the four tanks included in the scope of this report: S-106, S-102, SX-104, and SX-106 ${ }^{(a)}$. Finally, overall and tank-specific conclusions are given.

\subsection{Previous Work}

Saltwell pumping, or interim stabilization, is a well-established operation that began in the mid-1970s (Grimes 1978) for removing drainable interstitial liquid from SSTs. Of the 149 SSTs at Hanford, 45 have had drainable liquid removed by saltwell pumping. While saltwell pumping has been conducted in many tanks for years, only more recently have studies focused on understanding how it releases retained flammable gases. The first quantitative studies of gas release during saltwell pumping were associated with the safety assessment for saltwell pumping FGWL tanks conducted by Los Alamos National Laboratory (Meader 1996). As part of this safety assessment, the release rate of gas initially trapped in bubbles as a result of draining liquid from an SST was estimated (Spore 1996). However, the model neglected the release of soluble gases such as ammonia. In this model, it was assumed that, as the waste was drained, all of the trapped gas bubbles in the drained region were released. The consequence of this assumption is that the release rate is proportional to the pumping rate.

(a) Of these four tanks, three are Facility Group 2 tanks and SX-104 is in Facility Group 3, i.e. not likely to release significant amounts of flammable gas either spontaneously or induced by tank operations (Noorani 1997). 
Peurrung et al. $(1996,1997)$ conducted both modeling and laboratory studies of how draining liquid releases retained gas. The experiments focused on the release of gases from simulants that mimicked coarse saltcake. The model was used to elucidate the dominant gas release mechanisms in the laboratory experiments and to predict the gas release behavior from a typical tank during pumping. This study showed that draining liquid from a simple, homogeneous simulant released essentially all of the retained gas in a controlled manner. The model predictions showed controlled release of insoluble gas (hydrogen) and a very prolonged release of the dissolved gas (ammonia). In heterogeneous waste, however, layers of fine material were found to significantly retard or even prevent the release of gas from lower levels because the tightly held liquid in the small pores acted as a seal. These studies improved understanding of gas release behavior and provided a model for actual tank behavior that has been verified against laboratory studies. Peurrung et al. (1997) included gas release predictions for generic, homogeneous waste tanks. However, until recently no tanks with a significant retained flammable gas volume had been pumped to provide the data needed to verify the model against actual waste behavior.

\subsection{Mechanisms of Gas Release During Saltwell Pumping}

Flammable gases are retained in tank waste both as gas bubbles and as dissolved gas (primarily ammonia). The principal mechanisms of bubble retention and details of specific bubble retention mechanisms have been discussed previously (Rassat et al. 1997, 1998; Gauglitz et al. 1994, 1995, 1996; Rassat and Gauglitz 1995; Stewart et al. 1996). Observations of bubble retention in actual SST and double-shell tank (DST) waste have also been reported (Gauglitz et al. 1996; Bredt et al. 1995; Bredt and Tingey 1996). For bubbles retained in simulated particulate waste (saltcake with coarse particles), the previous work showed that the morphology of the retained bubbles depends on a Bond number, which is a ratio of gravitational forces to surface tension. Where the waste has relatively coarse particles typical of saltcake (on the order of 10 to 100 microns) (Reynolds 1992; Herting et al. 1992), it is expected that the dominant bubble retention mechanism will be capillary force, that the bubbles will finger between the particles constituting the particulate medium, and that the bubble behavior during draining can be represented by a classical porous media approach.

Figure 1.1 depicts saltwell pumping in a SST that contains a drainable saltcake. Interstitial liquid drains through the screened interval of the saltwell and is removed by a pump. In the vicinity of the saltwell screen the fluid level is reduced most quickly, while the fluid level away from the well decreases more slowly. Draining the fluid draws air into the pores between the salt crystals. Once the air has invaded the pores and exposed previously trapped bubbles, the gas within these bubbles is released from the waste by diffusing into the tank headspace against the invading air. Also shown in the figure is the expansion of bubbles caused by the reduced hydrostatic head on the bubbles as the liquid is drained from the waste. When the gas void fraction is low, these bubbles simply will expand. For high gas fractions, the expanding bubbles will connect and flow upward. In general, the gas fraction that defines the transition at which 


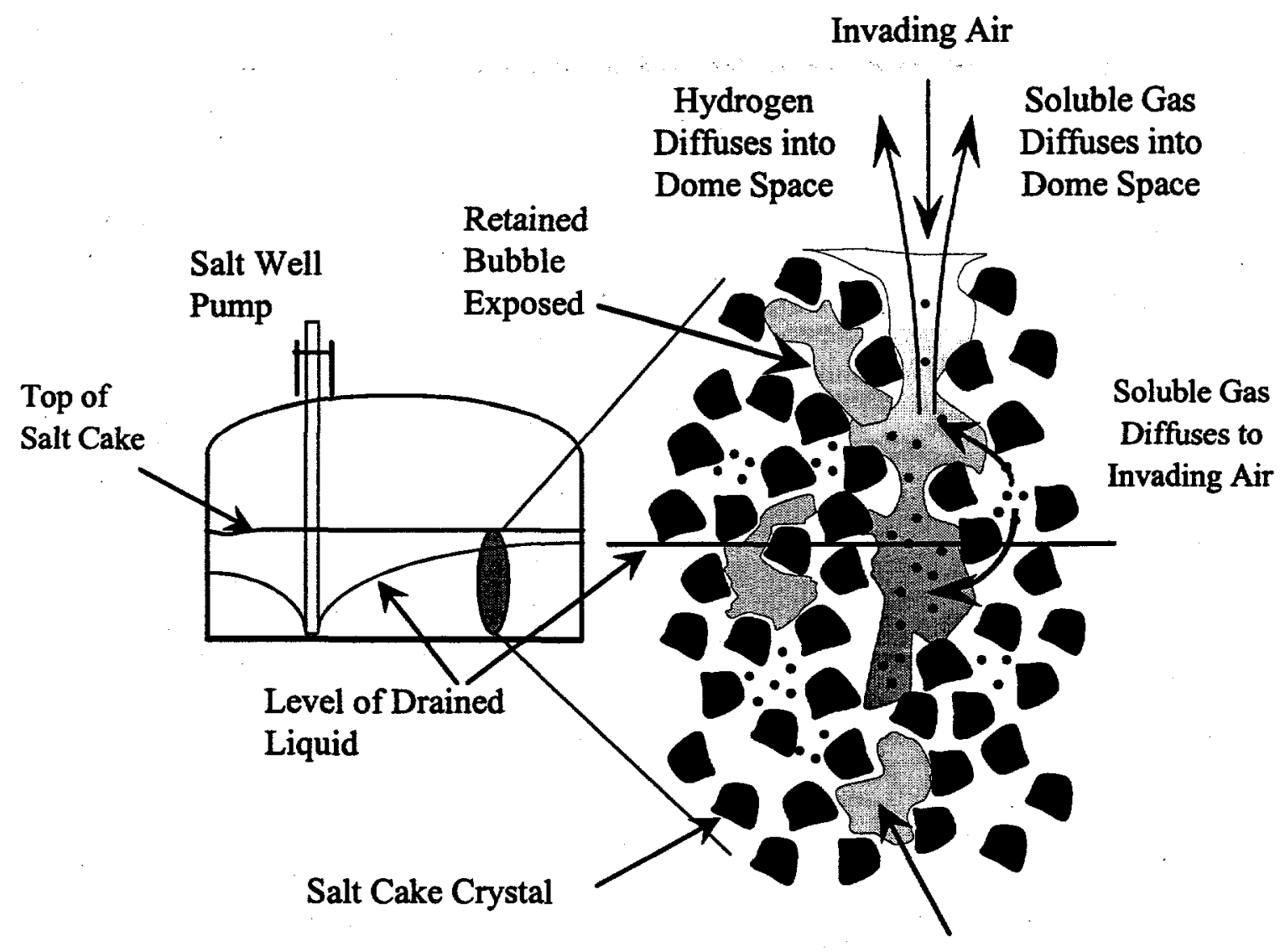

Retained Bubble Expands

Figure 1.1. Saltwell Pumping and Movement of Dissolved Soluble Gas. Draining interstitial liquid by saltwell pumping causes invading air to expose retained bubbles and retained bubbles to expand as fluid head decreases. Dissolved soluble gas (small dots) diffuses and partitions into invading air; both gas species then diffuse into tank headspace against invading air.

bubbles connect depends on the porosity and connectedness of the pores and the distribution of the retained bubbles. While this transition depends on many things that are difficult to measure, it is an easy parameter to vary in models.

Figure 1.1 also depicts the movement of dissolved soluble gas (primarily ammonia), which is shown as small dots. The dissolved soluble gas vapors diffuse through the aqueous phase and partition into the invading air. Once within the invading air, these vapors diffuse through the gas phase into the tank headspace. Naturally, the dissolved gases can also diffuse through the aqueous phase to the tank headspace, but diffusion through the aqueous phase is much slower than diffusion through the gas phase. 
Previous studies by Peurrung et al. $(1996,1997)$ evaluated the interplay between a number of mechanisms controlling the release of gas during draining. A series of experiments and computer simulations were conducted to explore a range of draining rates and column lengths, and both nitrogen and helium were used to represent the invading air. The draining rate studies were used to investigate the relative rates of upward diffusion and the downward velocity of the invading gas. Studies were conducted in which the downward velocity of the invading air dominated (fast draining), where these rates were equivalent, and where the downward velocity was negligible compared with the upward diffusion (slow draining). As depicted in Figure 1.1, the draining rate depends on the distance from the saltwell. The different column lengths and switching between nitrogen and helium (larger gas phase diffusions coefficient) allowed verification of the dominant role of gas phase diffusion on the release rates.

Peurrung et al. (1996) also reviewed the available data for porous media properties that should be expected for the actual SST waste and concluded that it was reasonable to assume that saltcake waste in SSTs will behave as a typical porous media in terms of how gases and fluids migrate. Simmons (1996) reviewed the liquid retention behavior of tank waste and was successful in understanding many aspects of tank draining by treating the waste as a permeable medium. Accordingly, our approach builds upon the traditional porous media concepts that have been successful so far. 


\subsection{Modeling Approach}

The conceptual model discussed in Section 1.2 has been incorporated into a computer code as described by Peurrung et al. (1997). The Subsurface Transport Over Multiple Phases (STOMP) computer code simulates flow and transport through porous media. It was developed at PNNL and has been used primarily for modeling soil hydrology. STOMP solves differential equations representing mass balances in air, water, and other phases (e.g., oil or ice) using the integral volume finite difference technique. Flows are Darcy-type based on the intrinsic and relative permeability of the porous medium and its liquid and gas phases. STOMP can also calculate an energy balance to solve nonisothermal problems, but this capability has not been used for this study.

Some changes to the model have been made for this study. First, trapped gas is no longer handled through the use of a hysteretic saturation function. Instead, a nonhysteretic Van Genuchten saturation function was employed. STOMP also has been revised so that the saltwell itself is modeled by an incorporated well model. For details on the mathematics and solution technique, see the STOMP manuals (White and Oostrom 1996, 1997).

STOMP models gas and liquid flow through an immobile, porous, solid phase. It is thus well suited for studying liquid draining and gas release during saltwell pumping. However, this report considers neither saltcake subsidence nor yielding of material. Dissolved gases, volatilized from solution, do not occupy volume in the gas phase due to an assumption that they are dilute. As discussed in Section 1, the validity of applying this model to tank waste depends on the degree to which saltcake behaves like a typical permeable material.

Previous tank modeling work (Peurrung et al. 1997) predicted hydrogen and ammonia release rates from a generic waste tank with typical dimensions and waste character. The physical and thermodynamic properties of the waste were taken, as available, from the Hanford literature or estimated using analogies to similar porous materials. As a basis, 100 standard cubic feet each of hydrogen and ammonia were assumed to be retained within the waste. The predictions assumed a pumping rate of $5 \mathrm{gal} / \mathrm{min}$ or the gravitational draining rate, whichever was lower. Pumping was continuous, though not at a constant rate.

STOMP simulations of tanks S-102 and S-106 were based on available tank-specific characterization data and daily pumping rates. Azimuthal symmetry was assumed, and the saltwell was placed at the center of the waste. The waste in tank S-102 was discretized into a 2dimensional grid of 370 nodes, 10 nodes in the radial direction by 37 nodes in the vertical direction. The waste in tank S-106 was discretized into analogous 10 by 34 node grid. Drainage parameters in the model (i.e., permeability and saturation function parameters) were adjusted in successive runs to fit the observed liquid level in the saltwell. Table 2.1 summarizes the values of the input parameters used in this study. 
Table 2.1. Values of Physical Parameters Used in the STOMP Simulations ${ }^{(2)}$

\begin{tabular}{|c|c|c|c|c|}
\hline Parameter & S-102 & S-106 & Units & Source/Basis \\
\hline Waste depth & 5.33 & 5.18 & m & \multirow{2}{*}{$\begin{array}{l}\text { Tank Characterization Database (PNNL } \\
\text { 1999) }\end{array}$} \\
\hline Liquid depth & 5.22 & 4.65 & $\mathbf{m}$ & \\
\hline Porosity of solid phase & 0.5 & 0.6 & Unitless & $\begin{array}{l}\text { Typical of porous solids without large } \\
\text { heterogeneities }\end{array}$ \\
\hline Hydraulic conductivity & 200 & 70 & Darcy & \multirow{3}{*}{ Fit observations of liquid drainage rate } \\
\hline van Genuchten alpha parameter & 8 & 3 & $1 / \mathrm{m}$ & \\
\hline van Genuchten n parameter & 3 & 1.3 & Unitless & \\
\hline Maximum residual gas saturation & 0.50 & 0.50 & Unitless & \\
\hline Maximum gas saturation & 0.50 & 0.50 & Unitless & \\
\hline Gas phase ammonia diffusivity & 0.25 & 0.25 & \multirow{3}{*}{$\mathrm{cm}^{2} / \mathrm{s}$} & \\
\hline Gas phase hydrogen diffusivity & 0.75 & 0.75 & & \\
\hline Gas phase nitrous oxide diffusivity & 0.16 & 0.16 & & \\
\hline $\begin{array}{l}\text { Initial ammonia vapor } \\
\text { concentration }\end{array}$ & $3 \%$ & $0.14 \%$ & \multirow{3}{*}{$\mathrm{mol} \%$} & \multirow{3}{*}{$\begin{array}{l}\text { S-102 data are preliminary }{ }^{(b)} \\
\text { S-106 data from Mahoney et al. (1997a) }\end{array}$} \\
\hline Initial hydrogen concentration & $32 \%$ & $63 \%$ & & \\
\hline Initial nitrous oxide concentration & $34 \%$ & $11 \%$ & & \\
\hline $\begin{array}{l}\text { Liquid phase diffusivity (all } \\
\text { species) }\end{array}$ & $0.04 \times 10^{-5}$ & $0.04 \times 10^{-5}$ & $\mathrm{~cm}^{2} / \mathrm{s}$ & $\begin{array}{l}\text { Typical of aqueous diffusion at the } \\
\text { corresponding liquid viscosity }\end{array}$ \\
\hline $\begin{array}{l}\text { Ammonia gas-aqueous partition } \\
\text { coefficient }\end{array}$ & 0.005 & 0.005 & \multirow{3}{*}{$\begin{array}{l}(\mathrm{mol} \text { gas } \\
\left./ \mathrm{m}^{3}\right) / \\
(\mathrm{mol} \text { aq } \\
\left./ \mathrm{m}^{3}\right)\end{array}$} & Norton and Pederson (1994) \\
\hline $\begin{array}{l}\text { Hydrogen gas-aqueous partition } \\
\text { coefficient }\end{array}$ & $10^{10}$ & $10^{10}$ & & Treated as essentially insoluble \\
\hline $\begin{array}{l}\text { Nitrous oxide gas-aqueous } \\
\text { partition coefficient }\end{array}$ & 66 & 66 & & Schumpe model \\
\hline $\begin{array}{l}\text { Initial trapped gas saturation } \\
\text { (void fraction) }\end{array}$ & $\begin{array}{c}0.32 \\
(0.16)\end{array}$ & $\begin{array}{c}0.38 \\
(0.23)\end{array}$ & Unitless & See Sections 4.0 and 5.0 \\
\hline Air density & 1.2 & 1.2 & $\mathrm{~kg} / \mathrm{m}^{3}$ & Welty et al. (1984); $\mathrm{T}=25^{\circ} \mathrm{C}$ \\
\hline Liquid density & 1.39 & 1.43 & $\mathrm{~g} / \mathrm{cm}^{3}$ & $\begin{array}{l}\text { S-102 data from Eggers (1996) } \\
\text { S-106 data from Field et al. (1998) }\end{array}$ \\
\hline Liquid viscosity & 24 & 24 & $\mathbf{c P}$ & Meader $1996^{(c)}$ \\
\hline \multicolumn{5}{|c|}{$\begin{array}{l}\text { (a) For input parameter definitions, see White and Oostrom } 1997 . \\
\text { (b) Mahoney LA, ZI Antoniak, and JM Bates. 1998. Preliminary Retained Gas Sampler Measurement Results for Hanford Waste } \\
\text { Tank 241-S-102. Letter Report TWS98.50, Pacific Northwest National Laboratory, Richland, Washington. } \\
\text { (c) This viscosity value is cited in Appendix G of reference. }\end{array}$} \\
\hline
\end{tabular}




\subsection{Estimation of Gas Release Rates}

This section describes how headspace flammable gas concentration data were taken and how they were converted to volumetric rates of gas release from the waste. This conversion requires the headspace ventilation rate, which can be determined by injecting a tracer gas into the headspace and measuring the rate at which its concentration decays.

\subsection{Method Description}

The rates of gas release from the waste were converted from measurements of gas concentration by applying a mass balance on the gas of interest in the tank headspace. The mass balance specifies that the amount of gas released during a given time period is equal to the amount that has accumulated in the headspace plus the amount that has been removed by ventilation. (It is assumed here that no other depletion mechanisms are significant compared to ventilation.) In addition to certain physical parameters (e.g., headspace volume), this requires knowledge of the headspace gas concentration and the headspace ventilation rate as functions of time.

The tanks of principal interest in this study have dedicated instrumentation in the Standard Hydrogen Monitoring Systems (SHMS) for measuring headspace gas concentrations at regular time intervals. Headspace ventilation rates are not measured routinely, however, and only an approximate value can be estimated a priori. Determination of the ventilation rate is thus the limiting factor for measuring the gas release rates in most tanks.

As part of this study, then, the ventilation rate of tank S-106 was determined using a tracer gas method. The method applied to tank S-106 was very similar to the tracer method successfully used to measure ventilation rates of other passively ventilated high-level waste tanks, including tank S-102, and has been discussed elsewhere (Huckaby et al. 1997a, 1998). As in the previous tracer studies, helium was injected into the headspace, and the decrease in helium concentration was measured periodically. The helium concentration decreases with time because it is removed by ventilation, and the rate at which it decreases can be used to calculate the ventilation rate. Previous tracer gas studies required that samples of the headspace be collected to determine the helium concentration, but in the current study of tank S-106 use was made of a gas chromatograph (GC) in the SHMS to measure helium directly.

Headspace concentrations of hydrogen, nitrous oxide, methane, and ammonia in tank S-106 were also measured and recorded several times per hour by the SHMS. Hydrogen, helium, nitrous oxide, and methane were measured using an MTI Analytical Instruments, Inc. micro GC equipped with two columns with integral thermal conductivity detectors (TCDs). A 10-m 5A molecular sieve packed capillary GC column with argon carrier gas was used to separate and measure the helium and hydrogen. An 8-m Poroplot- $Q$ capillary column was used to separate 
and measure methane and nitrous oxide. The GC/TCD was operated automatically, collecting and analyzing samples at approximately 10 -min intervals. Ammonia was measured using a Bruel and Kjaer photoacoustic infrared (IR) spectrometer that compensated for water vapor interferences. The spectrometer was also operated automatically, collecting and analyzing samples at approximately 2-min intervals. Daily calibration checks, using certified compressed gas standards, were performed on both the GC/TCD and the ammonia spectrometer. Data were retrieved during the semiweekly inspections of the SHMS.

The ventilation rate of tank S-102 was examined using the tracer gas method between September 24, 1996 and February 11, 1997 (Huckaby et al. 1997a). Both helium and sulfur hexafluoride were used as tracer gases in that study and were found to provide very similar estimates of the ventilation rate. Because no instrumentation was available on tank S-102 to monitor either tracer, headspace grab samples were collected and analyzed. The average ventilation rate for that period, based on the sulfur hexafluoride analyses of the 5 samples collected, was $3.8 \mathrm{~m}^{3} / \mathrm{h}\left(2.2 \mathrm{ft}^{3} / \mathrm{min}\right)$.

\subsection{Ventilation and Release Rate Calculations}

The tracer gas concentration in a tank headspace follows a first-order rate equation if several assumptions about the physical situation are satisfied. The tracer gas must be inert and insoluble in the waste, so that its only depletion mechanism is ventilation. The tracer must also be absent from, or at a relatively low constant level in, the ambient air introduced to the headspace. Also, the tracer must be uniformly distributed in the headspace so its concentration in the exhausted air is approximately its average concentration in the headspace. Under these conditions, the decrease in tracer concentration with time is proportional to its concentration:

$$
\frac{d C}{d t}=\frac{v}{V} C
$$

where $C$ is the concentration of the tracer, $v$ is the volumetric ventilation rate, $V$ is the headspace volume, and $t$ is time. This equation can be solved for the ventilation rate, $v$, between any two concentration measurements:

$$
v=\frac{V}{\left(t_{i}-t_{j}\right)} \ln \left(\frac{C_{j}}{C_{i}}\right)
$$

where $C_{i}$ and $C_{j}$ are the concentrations of the tracer gas at any two different times, $t_{i}$ and $t_{j}$, respectively. When concentration is plotted against time on a log-linear scale, the slope of the resulting line is proportional to the estimated ventilation rate.

Helium was injected into the tank S-106 headspace on April 15, 1999, and again on May 19,1999 , from standard compressed gas cylinders. Consistent with previous studies of 
headspace mixing in the Hanford waste tanks (Huckaby et al. 1997a, 1997b, 1998), rapid mixing of the injected helium was observed in tank S-106, and the helium concentration stabilized at approximately the anticipated concentration within 3 to 4 hours of injection.

The raw helium concentration data contain occasional bad (physically unreasonable) measurements, and it was apparent that measurements made shortly after the daily calibration were biased by the calibration run. Because identification and elimination of all bad data was impractical, average daily ventilation rates were based on helium concentrations recorded at midnight the day before and on the specified day. This allowed inspection of the individual data used and provided the best estimate of the total daily air exchange. Daily calibration checks indicated the GC/TCD to be operating properly and exhibiting little drift. Manual recalibration of the GC/TCD on several occasions caused discontinuities in the helium data. Helium concentration readings taken after a recalibration were linearly adjusted to correct for such changes.

Figure 3.1 depicts the helium concentration data after linear adjustments were made and with calibration data and identified bad data removed. The decrease in helium concentration

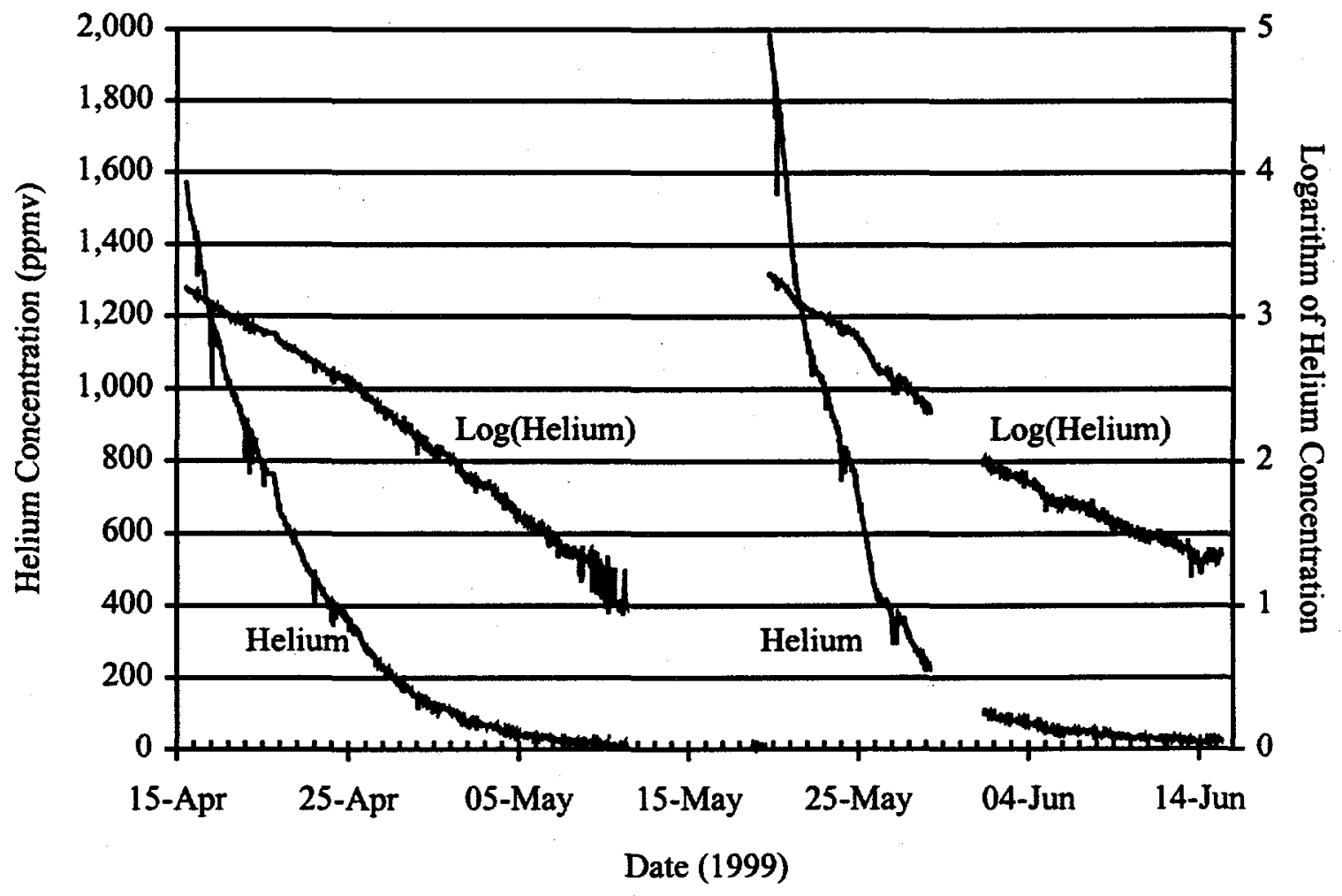

Figure 3.1 Tank S-106 Headspace Helium Tracer Gas Concentration and Logarithm of Concentration for Tracer Studies begun on April 15, 1999, and May 19, 1999 
with time is roughly exponential, and the logarithm of the helium concentration forms nearly a straight line. Deviation from linearity is evidence that the ventilation rate was not constant throughout the studies.

Table 3.1 lists the average daily ventilation rates for the two time periods studied. An instrument failure between May 29 and June 1 resulted in loss of data for that time period. Ventilation rates listed in Table 3.1 for those dates are based on interpolated helium concentrations. The overall average ventilation rate of the tank for both periods was $0.26 \mathrm{~m}^{3} / \mathrm{min}$ $\left(9.2 \mathrm{ft}^{3} / \mathrm{min}\right)$.

Table 3.1 Tank S-106 One-Day Average Ventilation Rates

\begin{tabular}{|c|c|c|c|}
\hline Date & $\begin{array}{c}\text { Ventilation Rate } \\
\left(\mathrm{ft}^{3} / \mathrm{min}\right)\end{array}$ & Date & $\begin{array}{c}\text { Ventilation Rate } \\
\left(\mathrm{ft}^{3} / \mathrm{min}\right)\end{array}$ \\
\hline $4 / 16 / 99$ & 10.7 & $5 / 19 / 99$ & 8.8 \\
\hline $4 / 17 / 99$ & 8.4 & $5 / 20 / 99$ & 14.6 \\
\hline $4 / 18 / 99$ & 7.0 & $5 / 21 / 99$ & 12.5 \\
\hline $4 / 19 / 99$ & $\overline{6.4}$ & $5 / 22 / 99$ & 6.0 \\
\hline $4 / 20 / 99$ & $\overline{8.8}$ & $5 / 23 / 99$ & 15.8 \\
\hline $4 / 21 / 99$ & 8.2 & $5 / 24 / 99$ & 3.0 \\
\hline $4 / 22 / 99$ & 9.3 & $5 / 25 / 99$ & 24.0 \\
\hline $4 / 23 / 99$ & 8.2 & $5 / 26 / 99$ & 15.7 \\
\hline $4 / 24 / 99$ & 6.8 & $5 / 27 / 99$ & 3.2 \\
\hline $4 / 25 / 99$ & 12.7 & $5 / 28 / 99$ & 15.4 \\
\hline $4 / 26 / 99$ & 11.9 & $5 / 29 / 99$ & 13.0 \\
\hline $4 / 27 / 99$ & 11.9 & $5 / 30 / 99$ & 12.9 \\
\hline $4 / 28 / 99$ & 11.1 & $5 / 31 / 99$ & 12.9 \\
\hline $4 / 29 / 99$ & 12.2 & $6 / 1 / 99$ & 12.4 \\
\hline $4 / 30 / 99$ & 5.9 & $6 / 2 / 99$ & 6.4 \\
\hline $5 / 1 / 99$ & 19.2 & $6 / 3 / 99$ & 5.2 \\
\hline $5 / 2 / 99$ & 3.6 & $6 / 4 / 99$ & 11.5 \\
\hline $5 / 3 / 99$ & 12.0 & $6 / 5 / 99$ & 7.2 \\
\hline $5 / 4 / 99$ & 14.5 & $6 / 6 / 99$ & 0.1 \\
\hline $5 / 5 / 99$ & 8.5 & $6 / 7 / 99$ & 9.1 \\
\hline $5 / 6 / 99$ & 10.2 & $6 / 8 / 99$ & 6.5 \\
\hline \multirow[t]{6}{*}{ Average } & 9.9 & $6 / 9 / 99$ & 6.7 \\
\hline & & $6 / 10 / 99$ & 5.8 \\
\hline & & $6 / 11 / 99$ & 0.6 \\
\hline & & $6 / 12 / 99$ & 7.9 \\
\hline & & $6 / 13 / 99$ & 12.1 \\
\hline & & Average & 8.6 \\
\hline
\end{tabular}


Daily gas release rates for hydrogen, nitrous oxide, and ammonia were calculated using mass balances on each gas. The rate each gas was removed by ventilation was calculated by multiplying the one-day average ventilation rate by the time-weighted average headspace concentration for that day. The time-weighted average was calculated after calibration check data and identified bad data had been removed from the raw concentration data set. The accumulation (or depletion) of each gas species in the headspace was calculated from concentration measurements taken at midnight on successive nights and an estimated headspace volume of $2,168 \mathrm{~m}^{3}\left(76,575 \mathrm{ft}^{3}\right)$.

Calculated gas release volumes for tank S-106 are given and discussed in Section 4. No tracer gas measurements were made during saltwell pumping operations in the other tanks in this report. Tank S-102 was assumed to be ventilated at the average rate measured in 1996 and 1997. Tanks SX-104 and SX-106 are actively ventilated at an estimated rate of about $1.4 \mathrm{~m} / \mathrm{min}(50$ $\left.\mathrm{ft}^{3} / \mathrm{min}\right)$. 


\subsection{Tank S-106}

Tank S-106 is a passively ventilated SST thought to retain significant amounts of gas. It is in Facility Group 2, but it is not on the FGWL. It has a capacity of $2,870 \mathrm{~m}^{3}(758,000$ gal). The tank was initially filled with waste from the REDOX facility, including aluminum cladding wastes, in the fifties and sixties. In the mid-seventies, it received evaporator bottoms from the 242-S Evaporator via tank S-102. The tank was removed from service in 1976. A liquid observation well was installed in 1980, and a jet pump was installed and activated in the fourth quarter of 1983 . From 1983 to $1984,378 \mathrm{~m}^{3}$ (99,800 gal) of liquid were removed via jet pumping. At the beginning of the current pumping campaign, the tank held about $1,813 \mathrm{~m}^{3}$ $(479,000 \mathrm{gal})$ of waste, of which $921 \mathrm{~m}^{3}$ (243,000 gal) was thought to be pumpable liquid (Schreiber and Barker 1998).

The bulk of the waste is saltcake. Historical surface level measurements taken through different risers and photographs of the waste indicate a pool of liquid in the central region of the waste (Brevick et al. 1997). The irregular surface of the waste surrounding the pool is approximately $0.6 \mathrm{~m}(2 \mathrm{ft})$ above the liquid pool surface. Coring records indicate the central pool of supernate may be several meters deep.

The gradual rise in waste surface level and waste surface level changes correlated with barometric pressure fluctuations indicate a significant amount of trapped gas exists in tank S-106. According to the tank characterization report (Field et al. 1998),

"A gradual increase in the surface level of the waste has been noted from 1989 to 1997. Tank samples and surface-level measurements indicate that the waste level in the tank is not uniform and the surface-level increase is likely a result of gas generation in liquids in the top central portion of the tank. The tank perimeter appears to have a hard (impenetrable) crust."

The void fraction of tank S-106 waste has been estimated from analyses of the barometric pressure effect (BPE) on waste surface level (Whitney 1995), and from analyses of retained gas samples (RGS) taken in February and March 1997 (Mahoney et al. 1997a). The BPE method indicates a total of $410 \mathrm{~m}^{3}$ of trapped gas (at tank conditions, Mahoney et al. 1997a), and the RGS method, based on three samples, estimates a total of $160 \mathrm{~m}^{3}$ of trapped gas. Historical waste surface level data suggest the higher estimate to be more likely. The BPE estimate is also based on a bulk property measurement, whereas the RGS estimate is based on four point sample measurements. The waste void fraction based on the BPE analysis is estimated to be about 0.23 , and this is the value used in STOMP calculations.

RGS analyses (Mahoney et al. 1997a) indicated that the average gas concentrations in the voids within the waste were $24 \%$ nitrogen, $63 \%$ hydrogen, $11 \%$ nitrous oxide, $0.14 \%$ ammonia, and $0.7 \%$ other gases. These values were used as input to STOMP. 


\subsection{Drainage Rate}

Saltwell pumping of tank S-106 began just before midnight on April 15, 1999. When the pump is on, the pumping rate varies from 0 to about $15 \mathrm{~L} / \mathrm{min}$ ( $4 \mathrm{gal} / \mathrm{min}$ ) of total liquids pumped. The bottom of Figure 4.1 shows the reported daily pumping volumes used in the simulation.

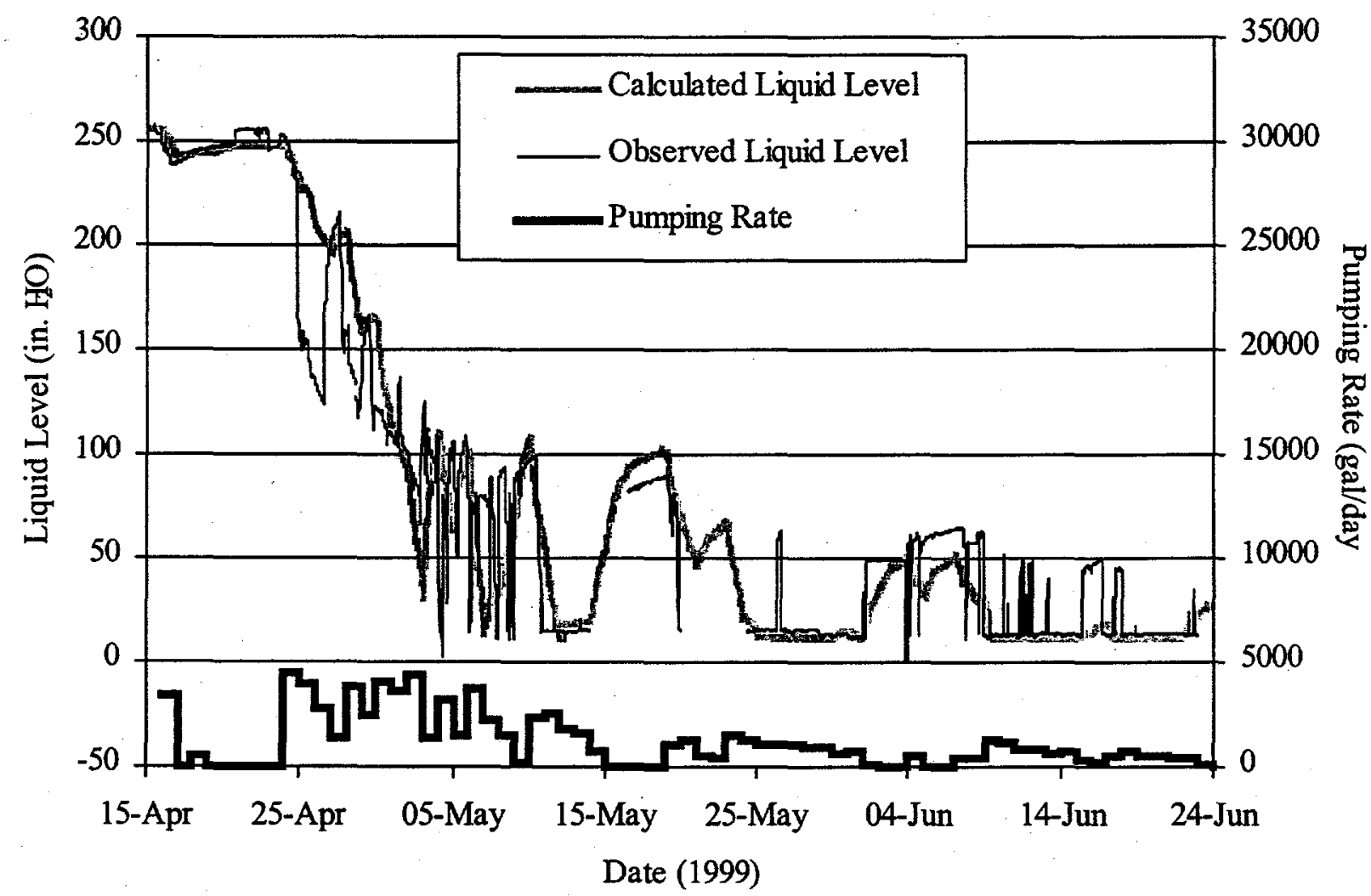

Figure 4.1 Tank S-106 Observed Saltwell Liquid Level (measured as a pressure differential between dip tubes in the headspace and at the bottom of the saltwell), Calculated Saltwell Liquid Level, and Daily Average Waste Pumping Rate as Functions of Date

The liquid level in the saltwell is measured as a pressure differential across dip tubes in the headspace and at the bottom of the saltwell. The saltwell liquid level, shown in the upper section of Figure 4.1, drops during pumping and refills by seepage when pumping is stopped. These draining/refilling data were used to approximate the shape of the central pool in the waste and determine three key drainage properties for the waste in the STOMP model. The drainage properties adjusted were the flow permeability, $k$, and the van Genuchten saturation function parameters, $\alpha$ and $n$, which govern the capillary behavior of gas and liquid within the waste (van Genuchten 1980). Small changes to the porosity of the waste from a default value of $50 \%$ were 
also permitted. These parameters were adjusted to achieve the best match between the observed liquid level fluctuations and the calculated liquid level. The best fit to the observed liquid level data is shown in Figure 4.1.

The size and shape of the central pool were found to strongly influence the calculated liquid level, particularly during periods of pumping. In the final simulation, the central pool was approximated as a 7-m-diameter cylinder extending $1.2 \mathrm{~m}$ below the surface of the waste (approximately $0.7 \mathrm{~m}$ below the liquid surface), with a 1.8 -m-diameter cylinder extending all the way to the bottom of the tank. This is depicted as the shaded region in Figure 4.2, where the simulation nodes have been drawn (roughly to scale) for a cross-section of the tank.

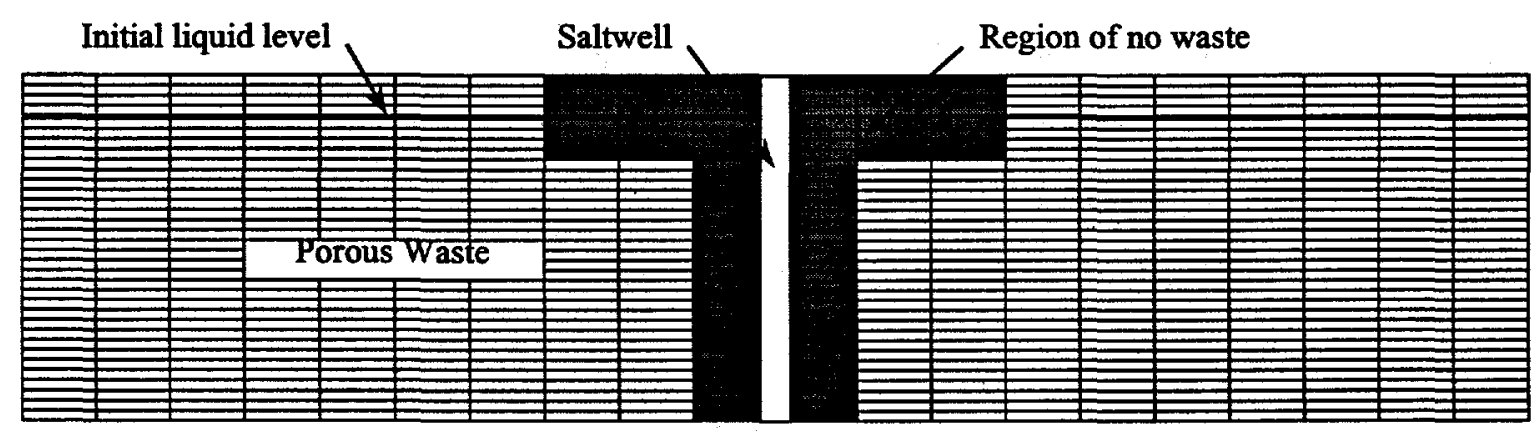

Figure 4.2 Grid Pattern for STOMP Simulation of Tank S-106

Adjustments of the waste permeability, $k$, were based primarily on the shape of the refilling cycle curve (that is, the way in which the liquid level recovers when pumping stops). The value used in the final simulation was 70 Darcy, which is a reasonable value based on previous permeability estimates for saltcake (Peurrung et al. 1996). The best-fit porosity was $60 \%$, indicating that this waste may be less tightly packed than expected, possibly due to soliddisplacing bubbles. The van Genuchten $\alpha$ and $n$ parameters specify the amount of liquid left in the porous waste as the liquid level decreases (the residual saturation). These were adjusted to increase or decrease the predicted amount of liquid drained and the amount of well refilling during breaks in pumping. The values selected, $\alpha=3.0 \mathrm{~m}^{-1}$ and $n=1.3$, indicate the saturation properties of the waste are similar to that of "sandy clay" or "clay loam" (Carsel and Parrish 1988). This analogy does not seem unreasonable for saltcake. The value of $\alpha$ selected is the same as in previous studies (Peurrung et al. 1997), while $\mathrm{n}$ is somewhat lower. The effect of decreasing $n$ is to broaden the capillary fringe, the region just above the liquid level where the waste transitions from very wet to well drained.

The agreement between observed and calculated liquid level illustrated in Figure 4.1 is reasonably good. The fit is qualitatively reasonable, and the simulated pumping volume as of 
June $24\left(285 \mathrm{~m}^{3}\right)$ agrees reasonably well with the reported pumping volume $\left(324 \mathrm{~m}^{3}\right)^{(a)}$. More detailed pumping rate data (instead of daily averages) could be used and would improve certain aspects of the fit, but experience with the simulation suggests the greatest single identifiable problem with the simulation was the specification of the size and shape of the central supernate pool. The assumption that the waste is homogeneous (i.e., physical properties are homogeneous and trapped gas is distributed homogeneously) was not evaluated in assessing the saltwell liquid level fit because of the associated increase in model complexity.

\subsection{Hydrogen and Nitrous Oxide Release}

The upper chart in Figure 4.3 shows the observed hydrogen, nitrous oxide, and ammonia concentrations in the headspace of tank S-106 for the early period of pumping, along with daily volume of waste pumped in the lower chart. Calibration and identified bad data points have been omitted from Figure 4.3. Periods of missing data are due to instrument problems. Not surprisingly, waste gas concentrations rose dramatically with the onset of pumping as gas bubbles were uncovered and released. However, the flammable gases remained below $7 \%$ of the lower flammability limit (LFL).

Periods of active pumping generally correlate with periods of higher gas concentration. Overall, however, the gas concentration levels appear to be quite flat; that is, reducing the pumping rate or turning the pump off does not reduce the concentrations rapidly. While one would expect the ammonia concentration to be roughly constant because of its prolonged release behavior, this behavior is surprising for hydrogen and nitrous oxide, which were expected to diffuse out of the waste and dissipate from the headspace rapidly. Moreover, late in pumping when the amount of liquid pumped per day is small, it was expected that correspondingly smaller amounts of all gases would be released, and that their headspace concentrations would fall.

Figure 4.4 contrasts the hydrogen release rate calculated from observations with that of the STOMP simulation. The measured release rates compared to the STOMP predictions are quantitatively and qualitatively different. First, STOMP predicts release rates that are significantly higher than what is observed. Second, the STOMP predictions show release rates that rapidly fall (from $300 \mathrm{ft}^{3} /$ day of hydrogen to essentially zero) as pumping slows and then stops. The actual data show a more or less constant release of about $25 \mathrm{ft}^{3} /$ day. The simulated and actual cumulative volumes of hydrogen released, shown in Figure 4.5, also illustrate these differences. Ventilation rate and hydrogen concentration data indicate that less than $2,500 \mathrm{ft}^{3}$ of hydrogen have been released after three months of pumping, while STOMP predicts that about $9,100 \mathrm{ft}^{3}$ would be released. Nitrous oxide release results are similar, as shown in Figures 4.6 and 4.7.

(a) This agreement is not automatic nor a constraint of the simulation. When the saltwell liquid level drops to 12 -in. $\mathrm{H}_{2} \mathrm{O}$ pressure, the STOMP well model reduces the pumping rate (below that specified by the user) to match seepage. 


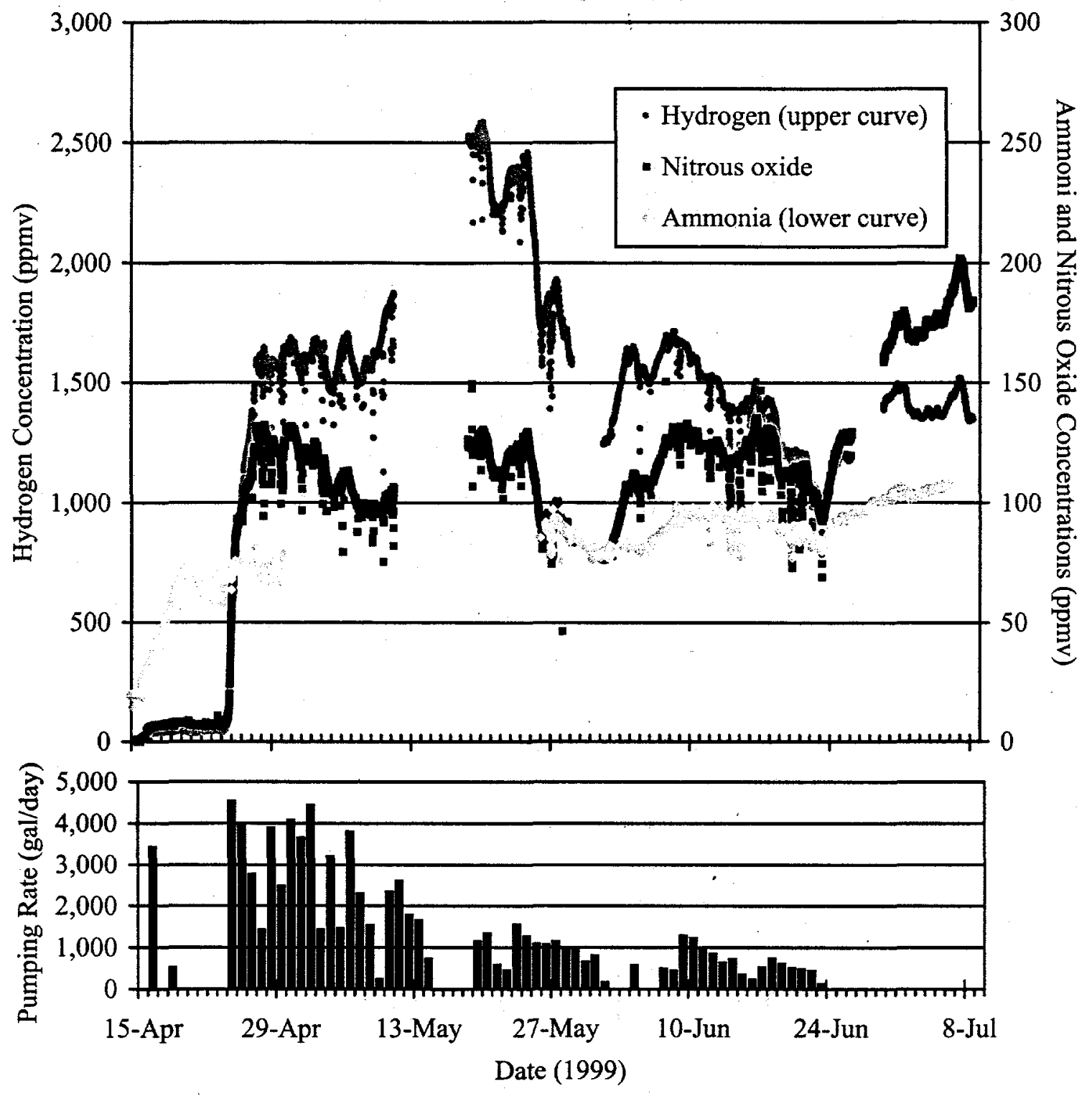

Figure 4.3 Hydrogen, Nitrous Oxide, and Ammonia Concentrations in the Tank S-106 Headspace, with Daily Pumping Volumes as Functions of Date 


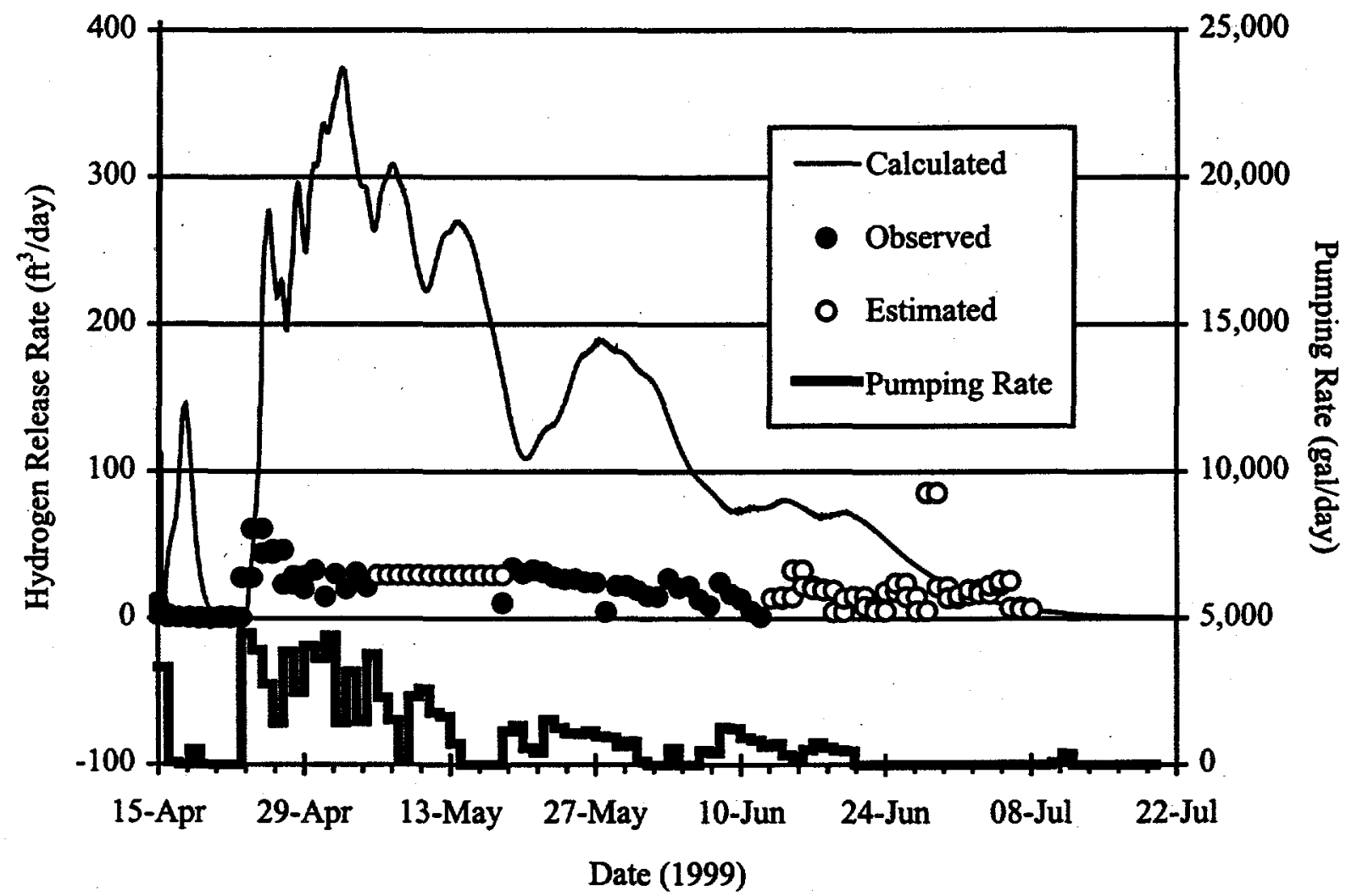

Figure 4.4 Tank S-106 Hydrogen Release Rate Calculated by STOMP (calculated), based on Measured Ventilation Rate and Concentration Data (observed), and Estimated from Average Ventilation Rate and Interpolated Concentration Data (estimated)

If estimates of the void fraction and composition of the gas in the waste are correct, the initial inventories of hydrogen and gas phase nitrous oxide in the tank are 13,000 and 2,300 standard cubic feet (SCF), respectively. STOMP predicts that by 83 days over $85 \%$ of the hydrogen and over $75 \%$ of the gas phase nitrous oxide has been released from the waste. Table 4.1 compares the calculated and observed release volumes. The STOMP prediction for hydrogen release is over 6 times higher than observed, while the nitrous oxide release prediction is more than 12 times higher than observed.

The large discrepancies between measured and predicted volumes of gas released do not appear to be caused by overestimating the initial gas inventories. Reducing the void fraction from 0.23 to about 0.04 and decreasing the nitrous oxide concentration from $11 \%$ to about $5 \%$ would bring the predicted cumulative release volumes at 83 days into agreement with observations. However, not only does the 0.04 void fraction seem unlikely given the BPE analysis and observed surface level rise, but the resulting prediction would still fail qualitatively. The predicted gas release rate would still tail off as in Figure 4.4 and fail to predict the observed 


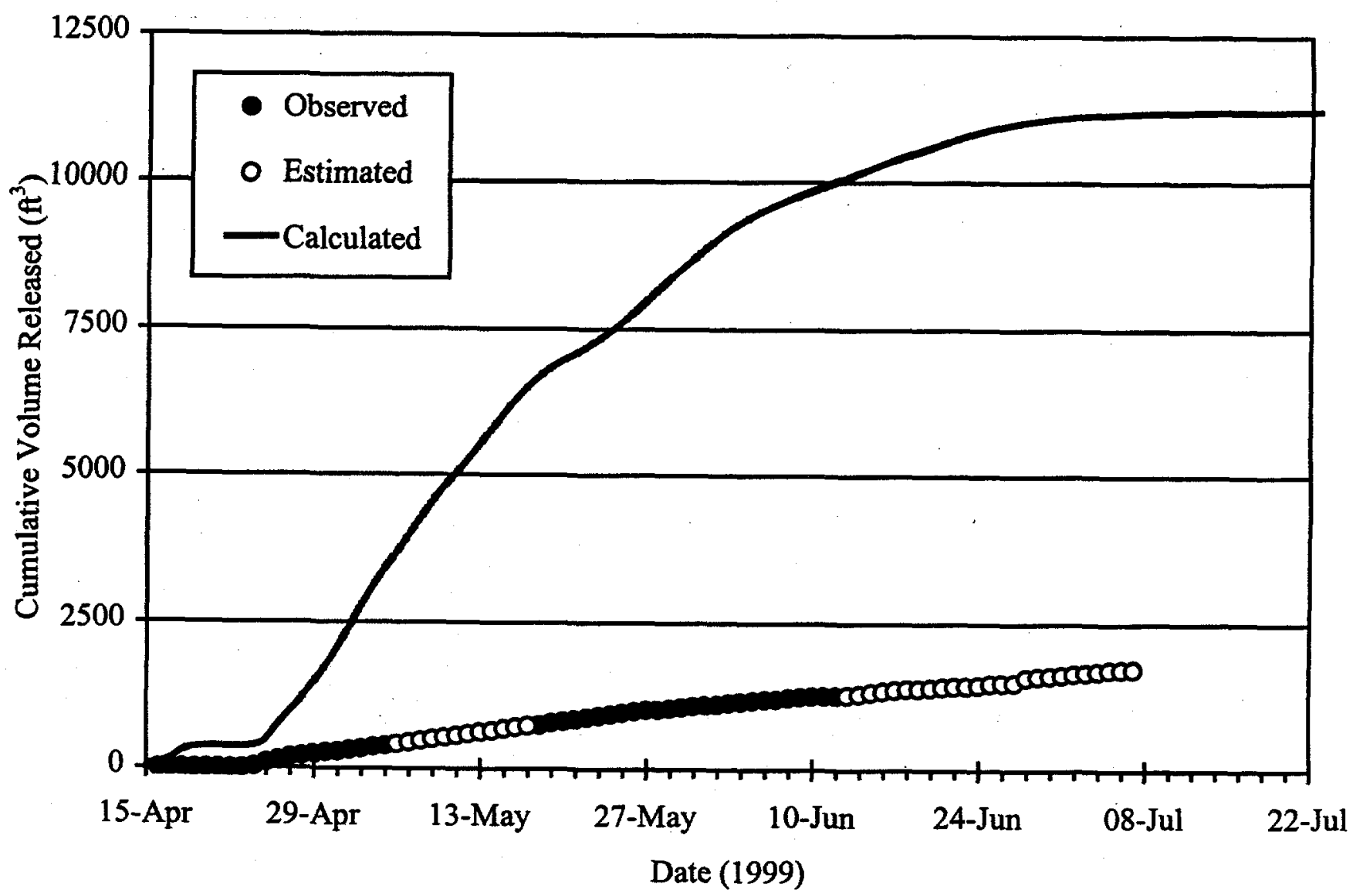

Figure 4.5 Tank S-106 Cumulative Released Hydrogen Volume Calculated by STOMP (calculated), based on Observed Ventilation Rate and Concentration Data (observed), and based on Average Ventilation Rate and Interpolated Concentration Data (estimated) 


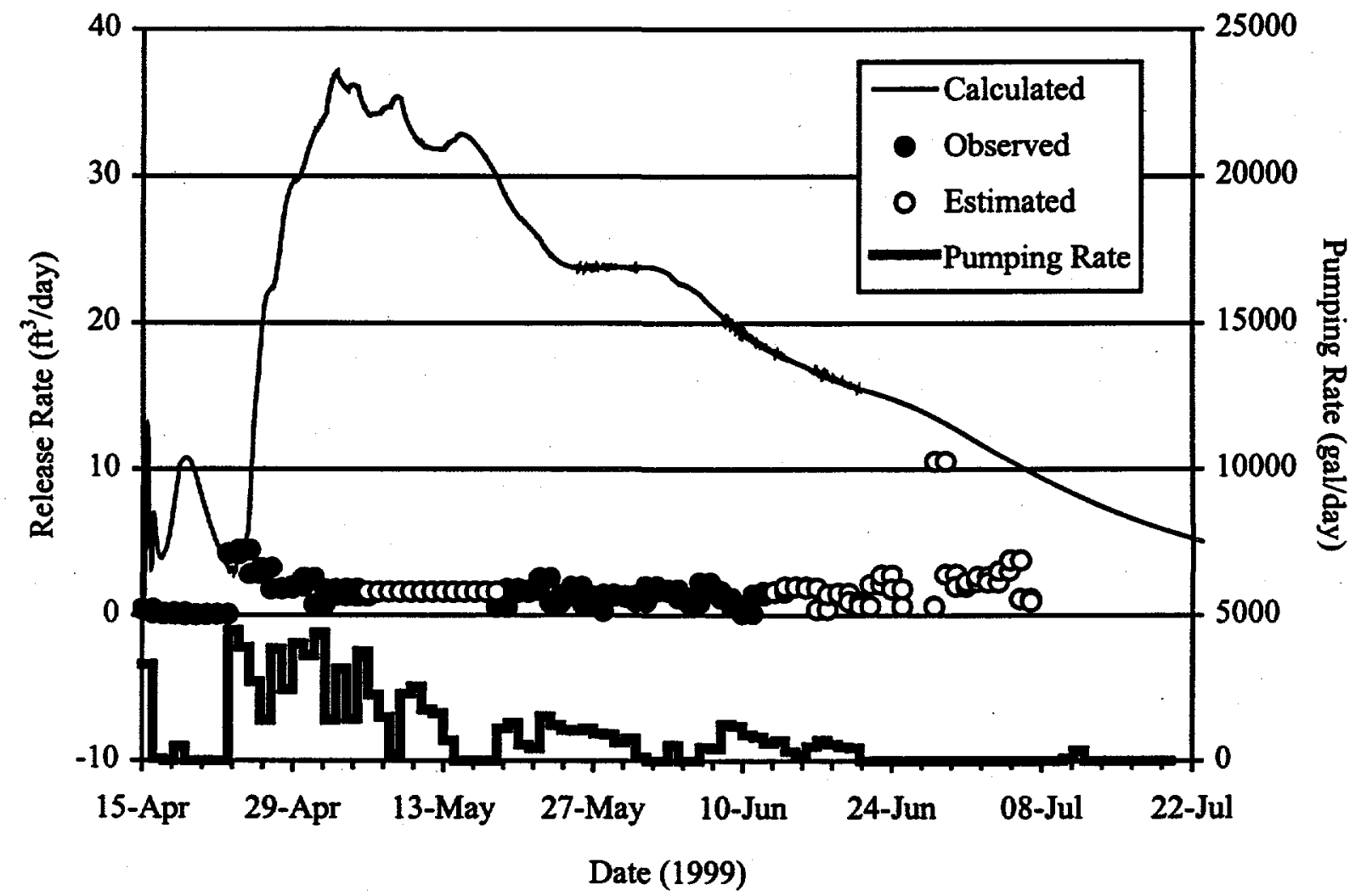

Figure 4.6 Tank S-106 Nitrous Oxide Release Rate Calculated by STOMP (calculated), based on Measured Ventilation Rate and Concentration Data (observed), and Estimated from Average Ventilation Rate and Interpolated Concentration Data (estimated) 


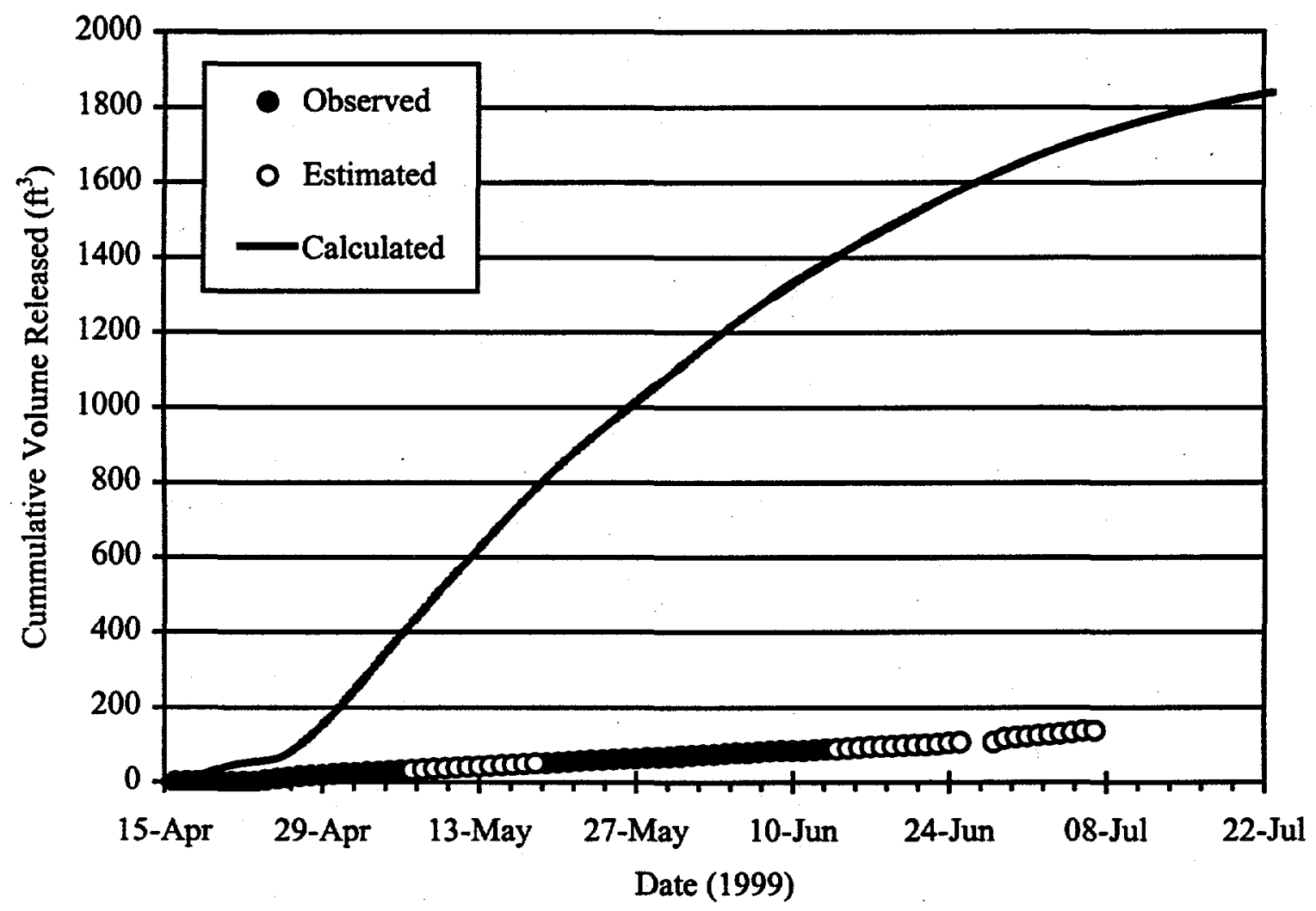

Figure 4.7 Tank S-106 Cumulative Released Nitrous Oxide Volume Calculated by STOMP (calculated), based on Observed Ventilation Rate and Concentration Data (observed), and based on Average Ventilation Rate and Interpolated Concentration Data (estimated) 
Table 4.1. Comparison of Measured and Predicted Cumulative Gas Volumes Released

\begin{tabular}{|l|c|c|c|}
\hline & $\begin{array}{c}\text { Estimated initial gas- } \\
\text { phase inventory } \\
\text { (SCF) }\end{array}$ & $\begin{array}{c}\text { Measured release } \\
\text { after 83 days } \\
\text { (SCF) }\end{array}$ & $\begin{array}{c}\text { Predicted release } \\
\text { after 83 days } \\
\text { (SCF) }\end{array}$ \\
\hline Hydrogen & 13,000 & 1,740 & 11,194 \\
\hline Nitrous oxide & 2,300 & 140 & 1,726 \\
\hline
\end{tabular}

sustained release of about $25 \mathrm{ft}^{3} /$ day. Though errors in the initial gas inventories may be contributing factors, it seems unlikely they are the primary source of the discrepancies.

Observed gas release rates appear to be relatively constant and unresponsive to changes in pumping rates, as illustrated in Figure 4.4. Table 4.2 lists the daily pumping volumes and calculated gas release rates and their averages during the two tracer studies conducted on tank S-106. Note that while the average daily volume of waste pumped during the second tracer study is only about one third that during the first study, the average daily volumes of hydrogen and nitrous oxide released during the two studies is about the same. Figure 4.8 further illustrates this point by plotting the volume of gas released against the volume of waste pumped. The straight line in the figure represents a simple waste-draining model in which uniformly distributed gas bubbles are simply released in proportion to the amount of waste drained and instantaneously disperse.

Clearly a simple draining model cannot account for the behavior of the observed data, nor can STOMP under its current set of assumptions. This suggests that the gas release rate may be controlled by mass transfer through the porous waste rather than by the rate at which trapped gas is freed. A homogeneous, uniformly drained waste would not normally produce such mass transfer limitations. However, Peurrung et al. (1997) observed in the laboratory that layers of fine-grained materials were capable of completely trapping gas beneath them, presumably because fine-grained media hold liquid tightly. While air can pass through the pores in such layers under a sufficient pressure drop (i.e., to allow drainage of liquid from below the layer), without a significant pressure drop the pore throats quickly refill with liquid and restrict gas flow.

Given that evaporator bottoms were transferred to tank S-106 from many campaigns, waste layering (horizontally contiguous or interrupted) is quite likely and might produce this effect. The observed prolonged release behavior could be due to slow transfer of waste gases upward through such layers. Transfer of gas through a layer of fine-grained material could be reduced to the rate it diffuses through the liquid, the rate bubbles penetrate the layer, or the rate gas diffuses around the edges of such barriers. 
Table 4.2 S-106 Gas Release Rates based on Measured Ventilation Rates and Headspace Concentrations

\begin{tabular}{|c|c|c|c|c|c|c|c|}
\hline Date & $\begin{array}{l}\text { Hydrogen } \\
\text { Volume } \\
\text { Released } \\
\left(\text { std. } \mathrm{ft}^{3}\right)\end{array}$ & $\begin{array}{l}\text { Nitrous } \\
\text { Oxide } \\
\text { Volume } \\
\text { Released } \\
\left(\text { std. } \mathrm{ft}^{3}\right)\end{array}$ & $\begin{array}{c}\text { Waste } \\
\text { Volume } \\
\text { Pumped } \\
\left(\mathrm{ft}^{3}\right)\end{array}$ & Date & $\begin{array}{l}\text { Hydrogen } \\
\text { Volume } \\
\text { Released } \\
\left(\text { std. } \mathrm{ft}^{3}\right)\end{array}$ & $\begin{array}{l}\text { Nitrous } \\
\text { Oxide } \\
\text { Volume } \\
\text { Released } \\
\left(\text { std. } \mathrm{ft}^{3}\right)\end{array}$ & $\begin{array}{c}\text { Waste } \\
\text { Volume } \\
\text { Pumped } \\
\left(\mathrm{ft}^{3}\right)\end{array}$ \\
\hline $4 / 16 / 99$ & 2.5 & 0.4 & 443 & $5 / 19 / 99$ & 10.7 & 0.6 & 0 \\
\hline $4 / 17 / 99$ & 0.6 & 0.2 & 11 & $5 / 20 / 99$ & 34.4 & 1.8 & 0 \\
\hline $4 / 18 / 99$ & 0.8 & 0.1 & 0 & $5 / 21 / 99$ & 30.9 & 1.6 & 75 \\
\hline $4 / 19 / 99$ & 0.5 & 0.2 & 66 & $5 / 22 / 99$ & 33.1 & 1.7 & 57 \\
\hline $4 / 20 / 99$ & 0.0 & 0.0 & 0 & $5 / 23 / 99$ & 31.5 & 2.6 & 205 \\
\hline $4 / 21 / 99$ & 0.7 & 0.1 & 0 & $5 / 24 / 99$ & 28.2 & 0.9 & 166 \\
\hline $4 / 22 / 99$ & 1.2 & 0.1 & 0 & $5 / 25 / 99$ & 26.7 & 1.4 & 142 \\
\hline $4 / 23 / 99$ & 0.5 & 0.1 & 0 & $5 / 26 / 99$ & 27.0 & 2.0 & 139 \\
\hline $4 / 24 / 99$ & 27.9 & 4.2 & 599 & $5 / 27 / 99$ & 24.9 & 0.8 & 149 \\
\hline $4 / 25 / 99$ & 61.1 & 4.5 & 506 & $5 / 28 / 99$ & 24.6 & 1.3 & 127 \\
\hline $4 / 26 / 99$ & 44.5 & 2.8 & 374 & $5 / 29 / 99$ & 27.1 & 1.7 & 121.9 \\
\hline $4 / 27 / 99$ & 46.7 & 3.2 & 193 & $5 / 30 / 99$ & 22.4 & 1.3 & 84 \\
\hline $4 / 28 / 99$ & 23.5 & 1.8 & 520 & $5 / 31 / 99$ & 19.6 & 1.3 & 104 \\
\hline $4 / 29 / 99$ & 28.8 & 1.9 & 330 & $6 / 1 / 99$ & 30.8 & 2.3 & 17.6 \\
\hline $4 / 30 / 99$ & 20.2 & 2.0 & 531 & $6 / 2 / 99$ & 27.4 & 2.0 & 0 \\
\hline $5 / 1 / 99$ & 32.9 & 2.5 & 484 & $6 / 3 / 99$ & 21.0 & 1.7 & 0 \\
\hline $5 / 2 / 99$ & 14.8 & 0.7 & 589 & $6 / 4 / 99$ & 22.2 & 1.8 & 72 \\
\hline $5 / 3 / 99$ & 30.4 & 1.8 & 188 & $6 / 5 / 99$ & 13.2 & 1.2 & 0 \\
\hline $5 / 4 / 99$ & 20.2 & 1.3 & 424 & $6 / 6 / 99$ & 8.9 & 0.8 & 0 \\
\hline $5 / 5 / 99$ & 31.4 & 1.8 & 193 & $6 / 7 / 99$ & 24.7 & 2.2 & 63 \\
\hline $5 / 6 / 99$ & 21.7 & 1.3 & 504 & $6 / 8 / 99$ & 17.0 & 1.6 & 55 \\
\hline Average & 19.6 & 1.5 & 283.6 & $6 / 9 / 99$ & 13.2 & 1.2 & 168 \\
\hline & & & & $6 / 10 / 99$ & 5.1 & 0.6 & 160 \\
\hline & & & & $6 / 11 / 99$ & 1.3 & 0.1 & 121 \\
\hline & & & & $6 / 12 / 99$ & 15.0 & 1.4 & 0 \\
\hline & & & & $6 / 13 / 99$ & 16.1 & 1.6 & 0 \\
\hline & & & & Average & 21.4 & 1.4 & 78 \\
\hline
\end{tabular}




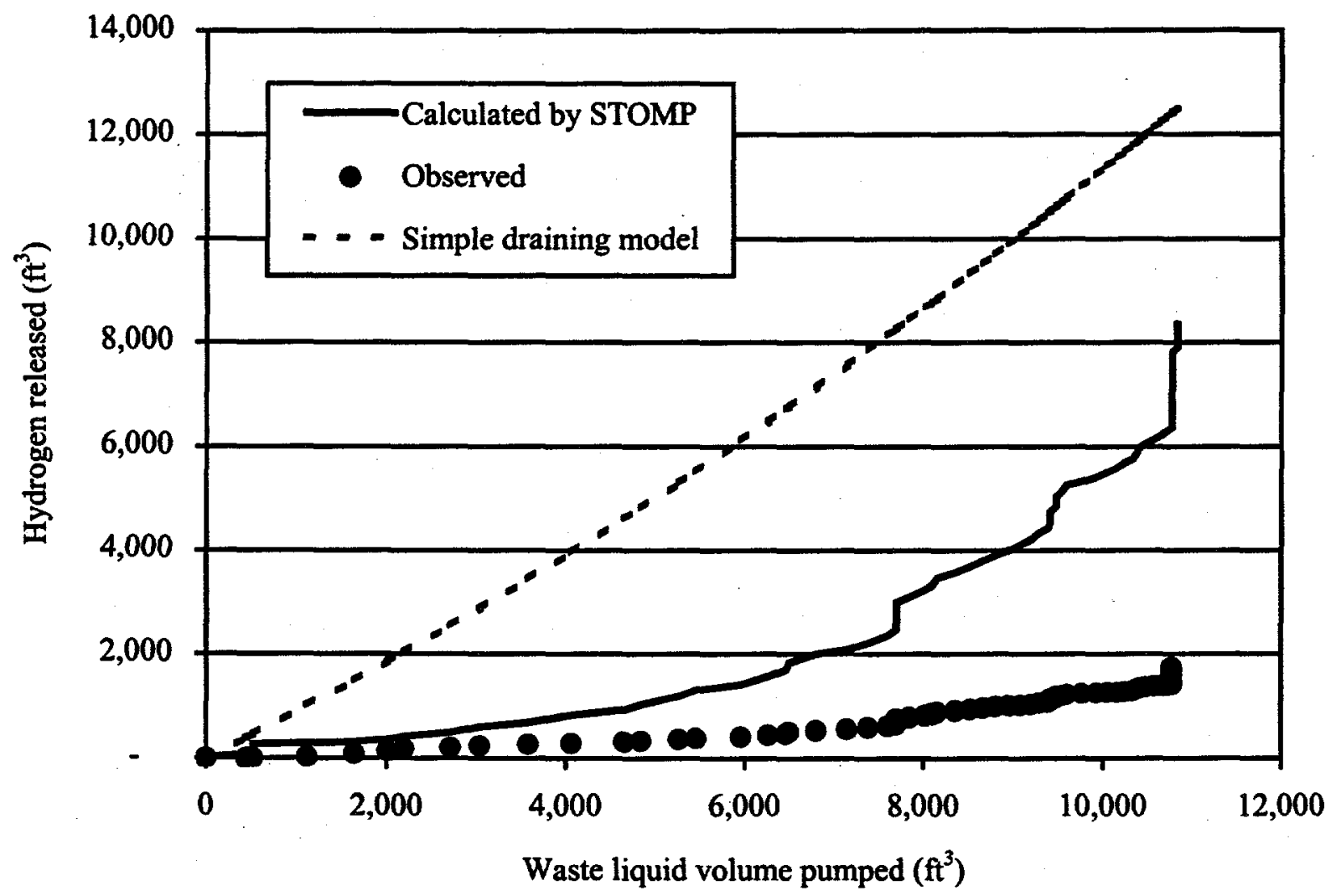

Figure 4.8 Comparison of Released Hydrogen Volumes for Tank S-106 Calculated by STOMP, by a Simple Draining Model, and Observed as Functions of Total Waste Pumped

As mentioned in Section 4.1, introducing heterogeneities to the modeled domain in STOMP was not considered practical. Instead, the effect of heterogeneity was examined by using effective gas-phase diffusion coefficients in STOMP equal to 0.1 and 0.01 times the normal binary diffusion coefficients. Results for hydrogen are plotted in Figure 4.9. When the effective diffusion coefficient was set equal to 0.01 times the normal diffusion coefficient, the model predicts a much more gradual release, consistent with the observed behavior at large times. The poor agreement at early times may be because whatever is impeding the transport of gas in the waste was below the region of waste initially drained, and had little effect on the release of gas above it. Similar results were obtained for nitrous oxide. 


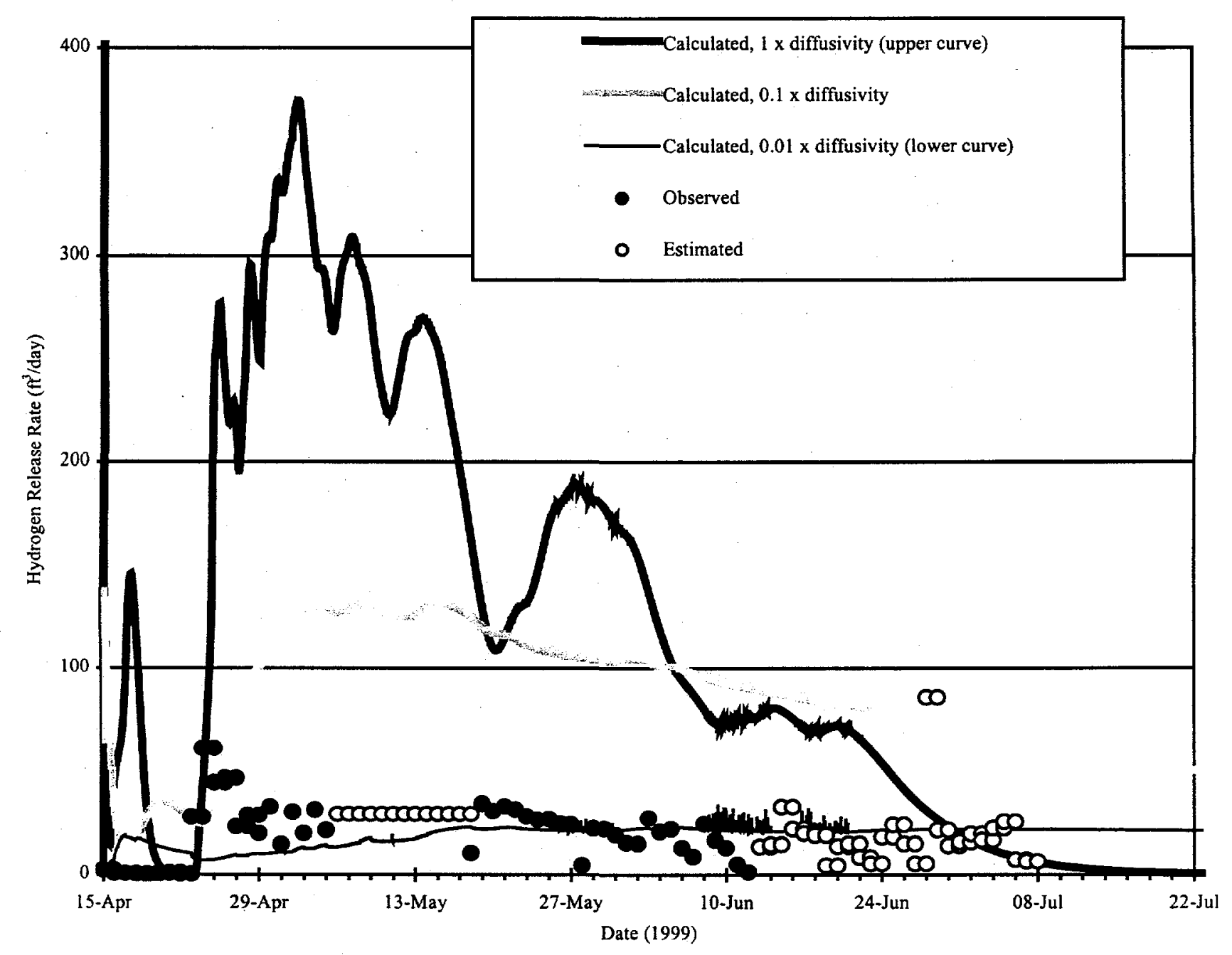

Figure 4.9 Comparison of Observed and Estimated Hydrogen Release Data for Tank S-106 with that Calculated Using the Regular and Two Effective Diffusivities for Hydrogen 


\subsection{Ammonia Release}

Unlike hydrogen and nitrous oxide, which are relatively insoluble in the aqueous waste liquid, ammonia is very soluble and preferentially stored in the liquid phase. Ammonia release is therefore controlled by the volatilization of dissolved ammonia from the partially drained waste above the liquid level (Peurrung et al. 1997).

Figure 4.10 shows the measured and predicted ammonia release rates along with the pumping rate. Both data and predictions show an ammonia release rate that is much more gradual than that of the insoluble gases (compare Figure 4.6), exhibits much less dependence on day to day changes in the pumping rate, and tails off much more gradually. Both predicted and measured cumulative volumes of ammonia released, plotted as functions of time in Figure 4.11, are relatively featureless.

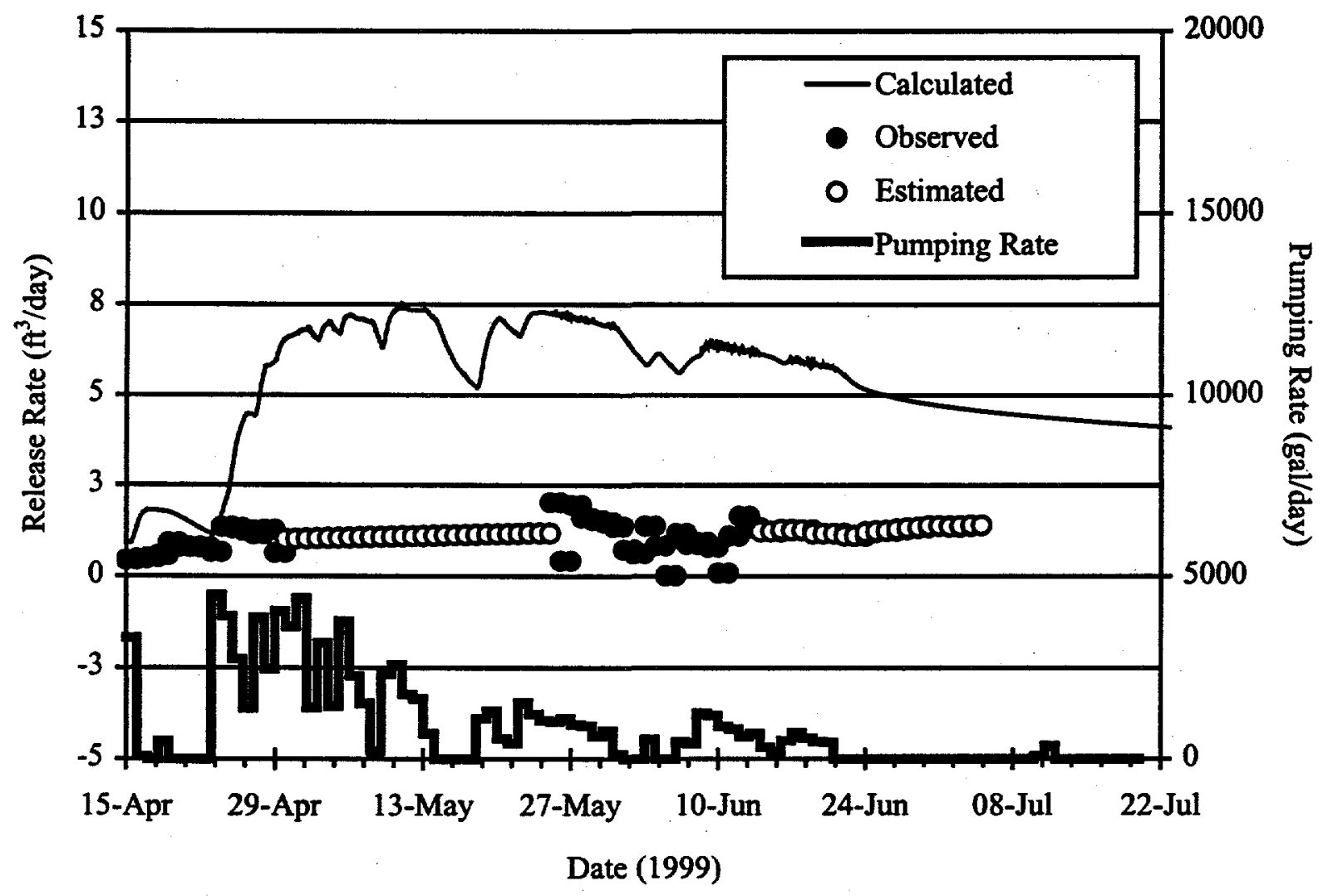

Figure 4.10 Tank S-106 Ammonia Release Rate Calculated by STOMP (calculated), based on Measured Ventilation Rate and Concentration Data (observed), and Estimated from Average Ventilation Rate and Interpolated Concentration Data (estimated) 


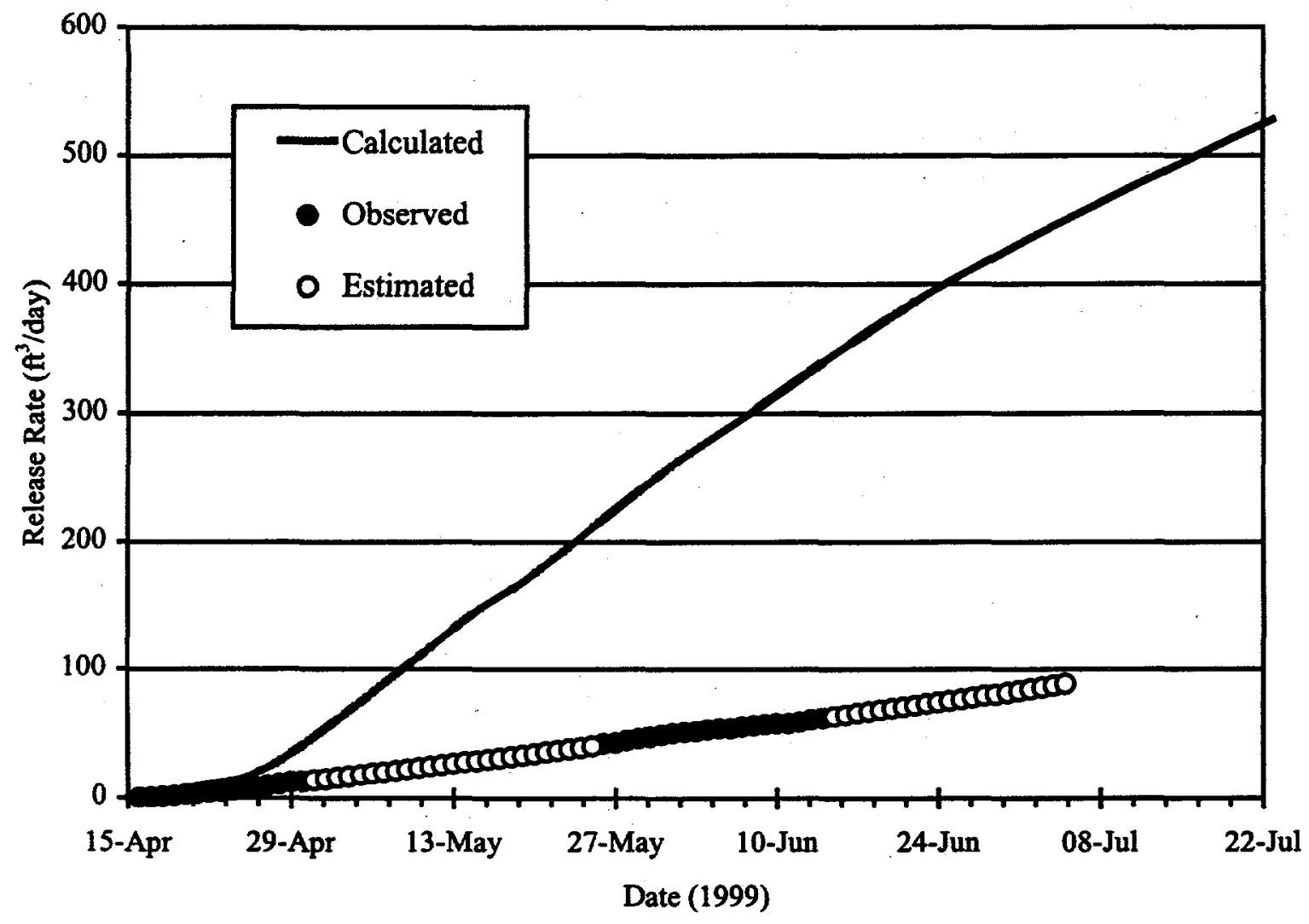

Figure 4.11 Tank S-106 Cumulative Released Ammonia Vapor Volume Calculated by STOMP (calculated), based on Observed Ventilation Rate and Concentration Data (observed), and based on Average Ventilation Rate and Interpolated Concentration Data (estimated)

However, STOMP again appears to over estimate the rate of release, in this case by a factor of four or five. It is more difficult in this case to argue for the presence of mass transfer limitations, because at this point in pumping most of the ammonia is still being depleted from liquid near the surface. One might postulate that the estimate of the ammonia inventory is incorrect. The estimated inventory is based on the gas-phase ammonia concentration measured by RGS (Mahoney et al. 1997a) and a partition coefficient based on the Schumpe model (1993). The Schumpe model is known to overestimate ammonia solubility when the salt content of the waste is high. There is also recognized uncertainty in the RGS ammonia concentration measurements. However, liquid grab samples taken from tank S-106 in November 1998 (PNNL 1999) indicate that the resulting estimated aqueous ammonia concentration of $190 \mu \mathrm{g} / \mathrm{mL}$ is correct to within at least a factor of two.

While the average liquid-phase concentration in the model appears to be correct, it is possible that some of the liquid near the waste surface is depleted in ammonia. Loss of ammonia by volatilization may have reduced the liquid-phase ammonia concentration near the surface. It 
is possible that this depleted region is retarding the ammonia release rates during pumping by absorbing ammonia released from deeper within the waste.

Although pumping is nearly complete, it is expected that ammonia will continue to volatilize from the residual liquid for years. If this hypothesis is correct, ammonia release rates should gradually increase as the uppermost liquid becomes re-saturated in ammonia, coming more in line with STOMP predictions.

\subsection{Conclusions for Tank S-106}

- The draining properties of the waste appear to match those of loosely packed sandy or loamy clay.

- Saltwell pumping is releasing hydrogen and nitrous oxide much more slowly than predicted by the model. Turning off the pump does not cause the release rate to fall quickly, as previously thought. Mass transfer limitations caused by waste heterogeneity may be the reason for this.

- Due to the slowness of the release, it is not clear yet whether pumping will ultimately release all of the retained gas.

- The ammonia release is prolonged, as expected. Disagreement between the magnitude of the observed release with the predicted release may be due to a depleted region near the waste surface. If so, ammonia release rates should eventually be more in line with STOMP predictions.

- Passive ventilation has been adequate to maintain gas concentrations well below the LFL. 


\subsection{Tank S-102}

Tank S-102 is also a passively ventilated SST in Facility Group 2. Unlike tank S-106, it is on the FGWL and was on the Organic Complexant Watch List until 1998. It is the same size as tank S-106 and served a similar early mission, accepting waste from the REDOX facility. From 1973 to 1976, it served as the feed tank for the 242-S Evaporator and was, therefore, involved in frequent waste transfers. From 1976 to 1979, it received evaporator bottoms and feed from tanks in SY, T, and TX farm. The tank was removed from service in 1980 and partially interim isolated in 1982. Some saltwell liquor waste was transferred out of the tank in 1992. At the beginning of the current pumping campaign, the tank held about $2,080 \mathrm{~m}^{3}(549,000$ gal) of waste, of which $848 \mathrm{~m}^{3}$ (224,000 gal) was thought to be pumpable liquid (Schreiber and Barker 1998).

The waste is almost entirely saltcake, $99 \%$ according to Hanlon (1999). A gradual rise in the level of waste has been observed, indicating gas retention. RGS samples were taken in 1998 that indicated a highly variable void fraction of $13-34 \%$ and average gas composition of $31 \%$ nitrogen, $32 \%$ hydrogen, $34 \%$ nitrous oxide, and $3 \%$ ammonia ${ }^{(2)}$. Given the variability of the samples, BPE analyses provide a better estimate of overall void fraction -0.16 or $429 \mathrm{~m}^{3}$ of trapped gas (at tank conditions) (Hodgson et al. 1997). The void fraction value used in STOMP calculations is therefore 0.16 .

\subsection{Drainage Rate}

Saltwell pumping of tank S-102 began March 18, 1999. As shown at the bottom of Figure 5.1, daily pumping volumes are variable. Pumping of tank S-102 has been delayed by several factors, including equipment and operation administration problems. As a result, as of July 9,1999 pumping was less than $15 \%$ complete.

The saltwell liquid level, measured as a pressure differential between dip tubes in the headspace and at the bottom of the saltwell, is plotted in Figure 5.1. The best fit to the observed saltwell liquid level data is also shown in Figure 5.1. Selection of model drainage parameters was based primarily on the observed liquid level data obtained through mid-April 1999. Sharp drops in the observed liquid level in late April and early May 1999 are not simulated by STOMP. This was in part because the model pumping rate input were based on reported daily pumping volumes, and input did not reflect short periods of high pumping rates properly. The observed liquid level data also exhibit several spikes after pumping was stopped in mid-May 1999. These spikes are associated with instrument flushes and recalibration of the instrument.

(a) Mahoney LA, ZI Antoniak, and JM Bates. 1998. Preliminary Retained Gas Sampler Measurement Results for Hanford Waste Tank 241-S-102. Letter Report TWS98.50, Pacific Northwest National Laboratory, Richland, Washington. 


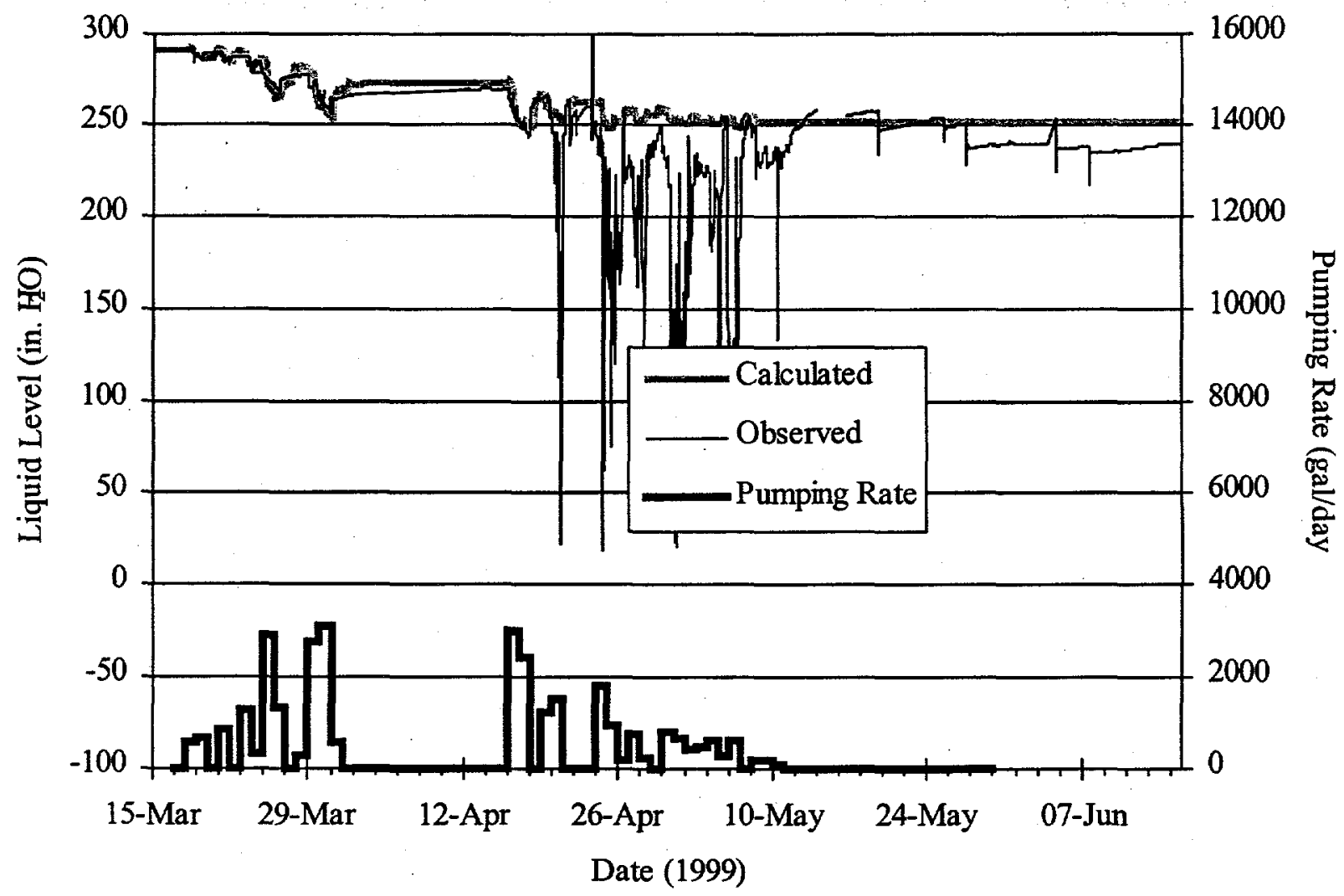

Figure 5.1 Tank S-102 Observed Saltwell Liquid Level (measured as a pressure differential between dip tubes in the headspace and at the bottom of the saltwell), Calculated Saltwell Liquid Level, and Daily Average Waste Pumping Rate as Functions of Date

The best fit shown in Figure 5.1 employed estimates of $k$, $\alpha$, and $n$ of 200 Darcy, $8 \mathrm{~m}^{-1}$, and 3 , respectively and a porosity of 0.5 . These values correspond to a coarser and somewhat more tightly packed material than was found for the waste in tank S-106, i.e. the waste is more like a true sand than a sandy clay or clay loam. As a result, the liquid level within the waste should be much more sharply defined, with a narrow transition region between drained and saturated material. The simulated pumping volume agrees identically with that reported, because pumping is not constrained by seepage at early times in tank S-102.

\subsection{Gas Release}

Figure 5.2 shows the hydrogen concentrations in the headspace of tank S-102 during pumping along with daily pumping volumes. The measured concentration values are close to the 


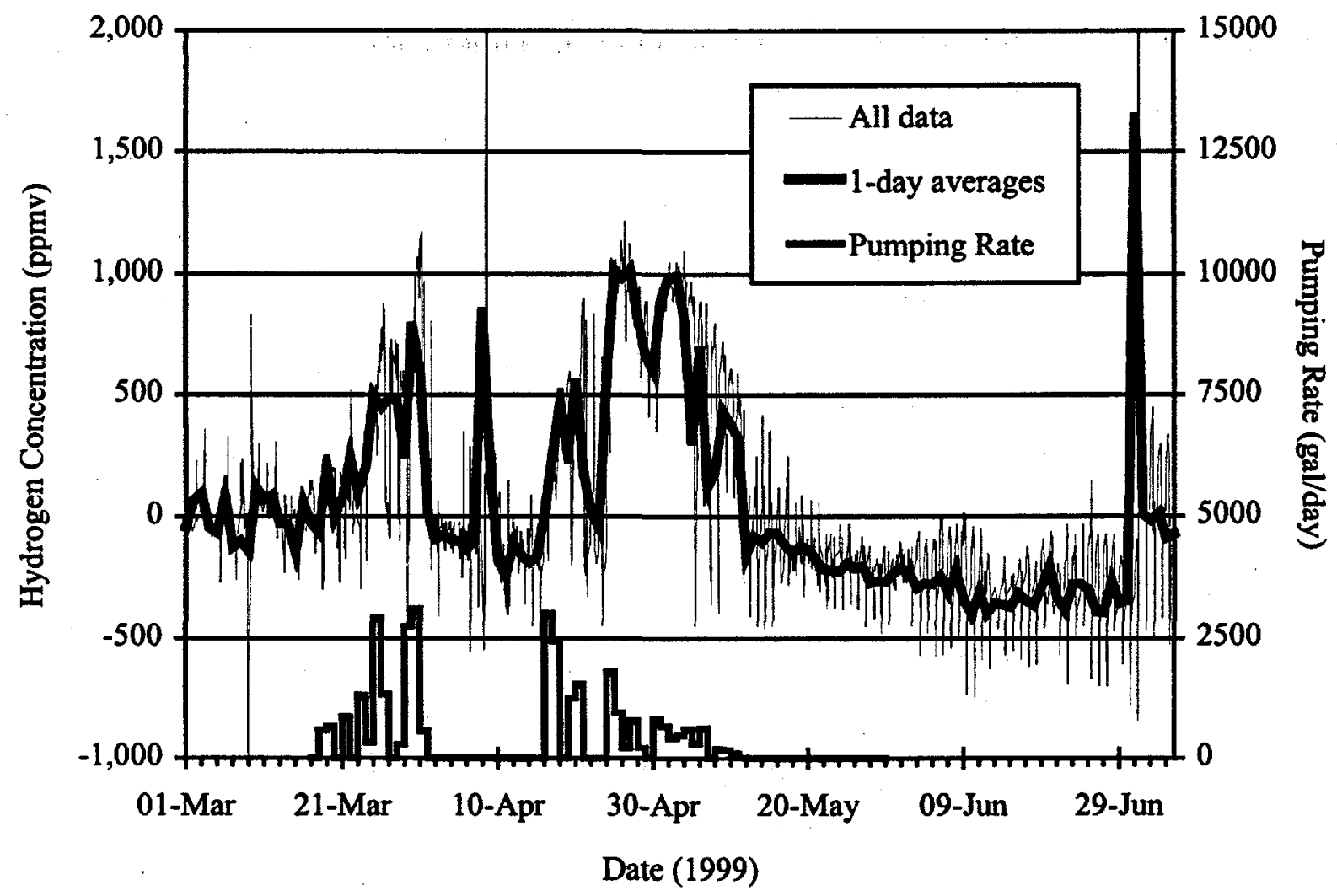

Figure 5.2 Tank S-102 Headspace Hydrogen Concentration and Reported Daily Pumping Rates

detection limit of the instrument, $100 \mathrm{ppmv}$ hydrogen. As a result, the data are quite noisy, so daily averages are also plotted. The baseline also appears to be trending downward, indicating a drift in instrument calibration.

In spite of the lower quality of the data, it is still apparent that headspace flammable gas levels rise significantly during periods of pumping. A few other spikes are seen in the hydrogen concentration curve, notably on April 8 and July 1, 1999, that do not correspond to pumping rates. These may be small gas release events.

The character of these data is significantly different than the tank S-106 data. Rather than showing a prolonged release, hydrogen concentrations fall quite rapidly when pumping stops and rise again when pumping resumes. For example, when pumping is stopped on April 1,1999, the hydrogen concentration drops rapidly back to its baseline concentration. This reaction time is only a day or two, characteristic of diffusion through a few meters of gas. This length is entirely consistent with the amount of waste drained at this point (about a meter) and a retardation factor of 2 to 3 due to pore tortuosity in a simple, homogeneous material. These results suggest that the waste (or at least at the upper portion of it) may be fairly homogeneous. 
For tank S-106, tracer gas data were used to measure instantaneous ventilation rates and convert headspace concentrations to release rates for comparison to STOMP. However, no tracer gas injections were made as part of the current study into tank S-102, introducing uncertainty into any conversion of the concentration data to gas release rates. Previously, Huckaby et al. (1997a) used a tracer to estimate the ventilation rate and found it to average $0.063 \mathrm{~m}^{3} / \mathrm{min}(2.2$ $\mathrm{ft}^{3} / \mathrm{min}$ ). Applying this average rate to the noisy and often negative data in Figure 5.2 yields a noisy release rate curve that is often negative and difficult to interpret. In this case, it makes more sense to apply the ventilation rate to the STOMP release rate predictions and compare them directly to the concentration data.

These data are shown in Figure 5.3, where a linearly increasing offset has been applied to the data to maintain a zero baseline. Qualitative agreement is good; however, note that the STOMP predictions are scaled on a secondary axis that differs from the primary axis by a factor of ten. In this case, released gas appears to diffuse out of the waste promptly, but the overall magnitude of the release is far smaller than expected. Specifically, STOMP predicts a release of $17 \mathrm{~m}^{3}$ of hydrogen, while the estimated amount actually released (assuming a ventilation rate of $0.063 \mathrm{~m}^{3} / \mathrm{min}$ ) is about $3.4 \mathrm{~m}^{3}$. The actual release data here includes the two small peaks uncorrelated to pumping that appear to be gas release events.

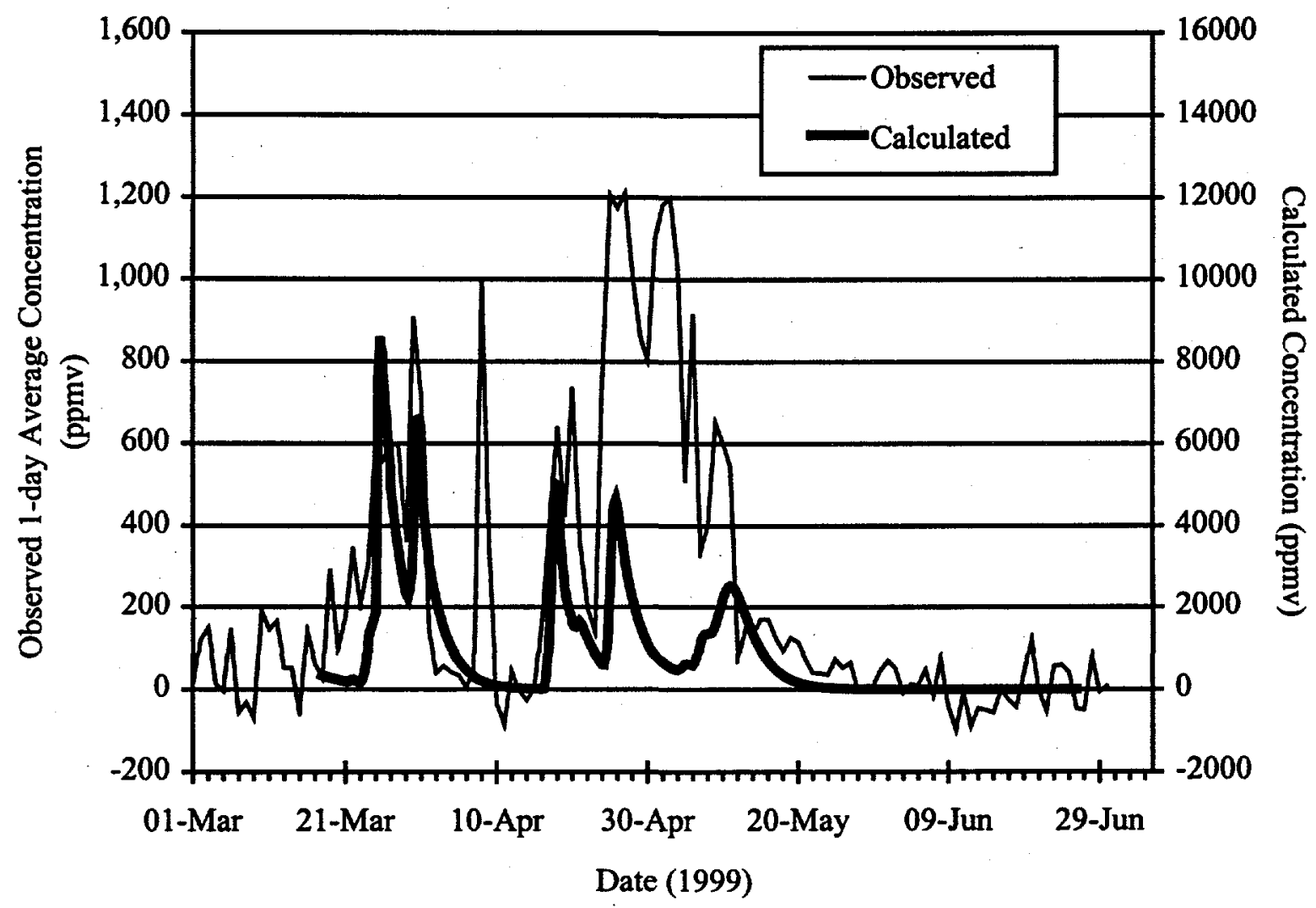

Figure 5.3 Tank S-102 Observed and Calculated Headspace Hydrogen Concentrations 
Again, one explanation that would be consistent with the data is that estimates of the void fraction or hydrogen content in the waste are too high. However, it is unlikely that these estimates are off by an order of magnitude.

Increasing the estimated ventilation rate would bring the magnitude of the STOMP concentration predictions down. However, it would also make the concentration peaks decay more rapidly, producing a more spiked curve. The factor of ten increase in assumed ventilation rate necessary to bring the magnitude of the two curves into agreement is not realistic, and would strain the qualitative agreement.

The waste heterogeneity arguments applied to the results from tank S-106 do not seem to be consistent with these data. Mass transfer limitations such as diffusion-blocking layers would result in a prolonged release, smoothing out the data. One could postulate heterogeneities in the form of large volumes of fine-grained material in the waste that have not been drained and, therefore, have not released their gas. If these hold $90 \%$ of the gas, though, then presumably they make up about $90 \%$ of the waste volume. In that case, in order to drain the amount of liquid pumped to date, the liquid level would need to be far lower - which is inconsistent with the pumping data and with the observed fast diffusion time.

An explanation that is consistent with the gas release data is that the uppermost portion of the waste is depleted in gas, either from liquid level fluctuations associated with barometric pressure changes, from void migration, or from other gas release phenomena. This hypothesis has some merit based on studies that show void fraction diminishing near the top of the settled solids layer in double-shell tanks (Peurrung et al. 1998). However, no consistent pattern of void depletion near the top of the waste has ever been found in SSTs. In fact, the RGS data taken in tank S-102 show quite the opposite, with segment 2 of the waste (which was nearest the top) containing $34 \%$ void, compared to an average void of $25 \%{ }^{\left({ }^{(a)}\right.}$ While the RGS data contradict this hypothesis, it is still considered the most plausible. If this hypothesis is true, future pumping should release significantly more hydrogen.

\subsection{Conclusions for Tank S-102}

- The draining properties of the waste appear to match those of a sand.

- Saltwell pumping appears to be releasing an order of magnitude less hydrogen than expected. The hydrogen that is released dissipates promptly in a manner consistent with gas-phase diffusion through the meter of waste that has been drained so far.

(a) Mahoney LA, ZI Antoniak, and JM Bates. 1998. Preliminary Retained Gas Sampler Measurement Results for Hanford Waste Tank 241-S-102. Letter Report TWS98.50, Pacific Northwest National Laboratory, Richland, Washington. 
- A potential explanation for the discrepancy between the observed and predicted release volumes is void depletion near the top of the waste. However, this hypothesis is at odds with RGS sampling.

- Passive ventilation has been adequate to maintain gas concentrations well below the LFL. 


\subsection{Tank SX-104}

Tank SX-104 is an actively, rather than a passively, ventilated SST on the FGWL. It is thought to retain much less gas than tanks S-106 or S-102 and is, therefore, in Facility Group 3. Hodgson et al. (1997) estimated the trapped gas volume in tank SX-104 to be $27 \mathrm{~m}^{3}\left(970 \mathrm{ft}^{3}\right)$ at tank conditions, before the onset of saltwell pumping. This corresponds to a void fraction of about 0.01 , based on a waste volume of $2,300 \mathrm{~m}^{3}$ (Hanlon 1999). The ventilation rate of tank SX-104 has not been measured recently, but is thought to be about $1.4 \mathrm{~m}^{3} / \mathrm{min}\left(50 \mathrm{ft}^{3} / \mathrm{min}\right)$ based on the total air flow of the SX-farm exhauster and the cascade position of tank SX-104 (a). The waste is $78 \%$ saltcake (Hanlon 1999). The tank was previously saltwell pumped in 1988 and 1989 , which removed $428.5 \mathrm{~m}^{3}$ (113,200 gal) of liquid (Stout et al. 1997). Prior to the onset of pumping in 1998, tank SX-104 had an estimated $2,211 \mathrm{~m}^{3}$ (584,000 gal) of waste, of which 876 $\mathrm{m}^{3}$ (231,000 gal) of pumpable liquid waste (Schreiber and Barker 1998).

Saltwell pumping of tank SX-104 began on July 23,1998 . As of July $25,1999,471 \mathrm{~m}^{3}$ $(124,500 \mathrm{gal})$ of waste had been pumped. Headspace hydrogen concentration data from a Whittaker cell are available for this tank. Because this tank is actively ventilated, hydrogen concentrations in the headspace are relatively low. In the unlikely event that tank SX-104 released hydrogen at a rate of $20 \mathrm{ft}^{3} /$ day (about the average observed rate for tank S-106) for a sustained period, given a ventilation rate of $1.4 \mathrm{~m}^{3} / \mathrm{min}$, the hydrogen concentration would only approach $280 \mathrm{ppmv}$. At the observed hydrogen concentrations, the instrument suffers from limitations on its precision, daily fluctuations in its readings due to temperature changes in the cell, and the tendency for its zero point to drift. As a result, the data do not provide detailed information on gas releases. Hence, though the data are presented here, no STOMP simulation was performed.

Figure 6.1 shows the raw hydrogen concentration data and the daily pumping volumes. The large spikes are due to instrument calibrations and do not represent gas releases. There is no discernible change in flammable gas level at the beginning of pumping in these data. Expanding the y-axis and calculating a daily average concentration, shown in Figure 6.2, reveals an upward trend in the level beginning three months or so after pumping begins. However, this fluctuation is comparable to other long-term fluctuations in the data before pumping and so may not be significant.

(a) Letter report TWS99.42 from J Brothers (PNNL) to GD Johnson (LMHC), June 14, 1999, Draft Chapter 7 for Flammable Gas Topical Report. 


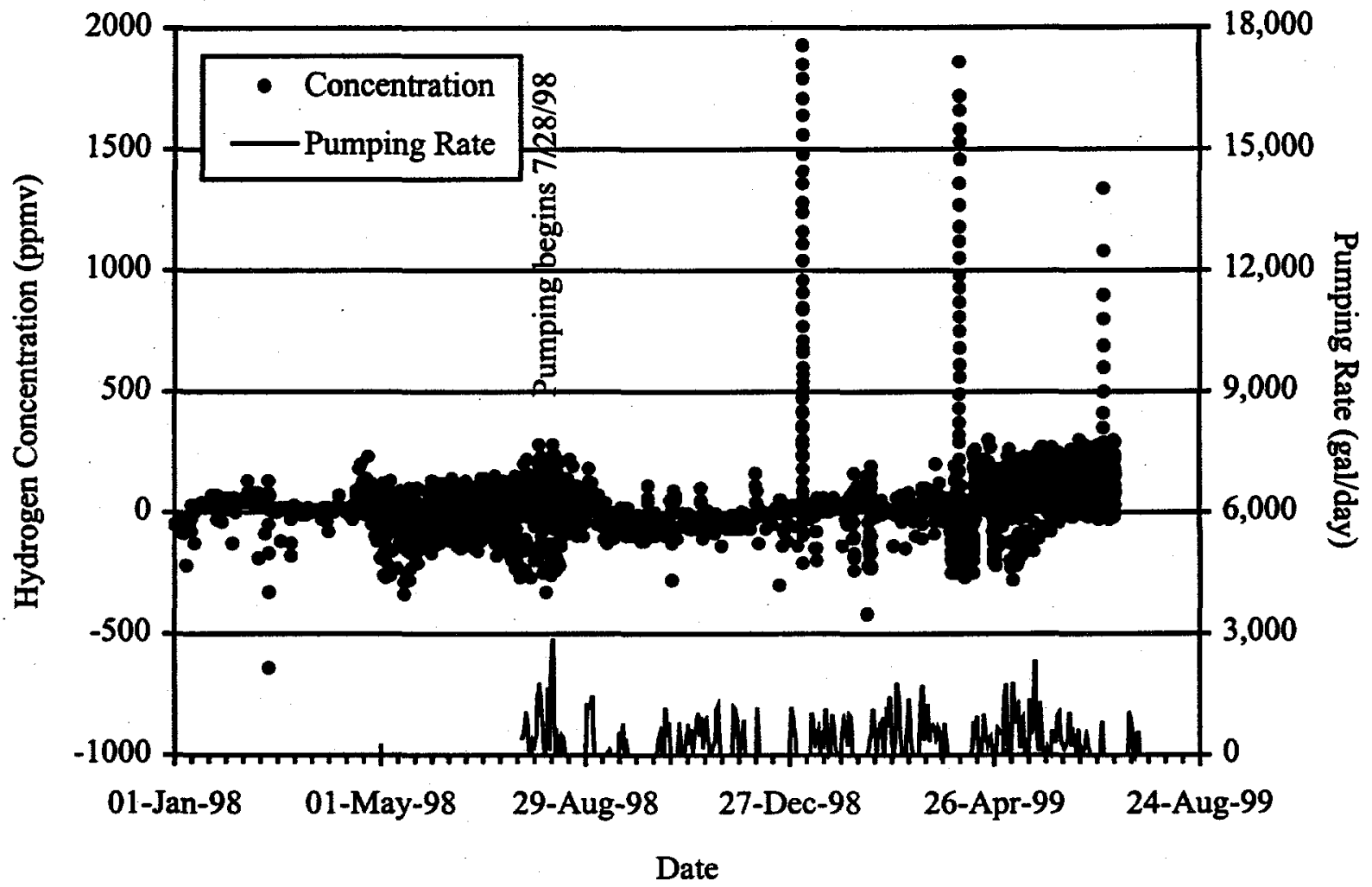

Figure 6.1 Tank SX-104 Headspace Hydrogen Concentration and Pumping Rate 


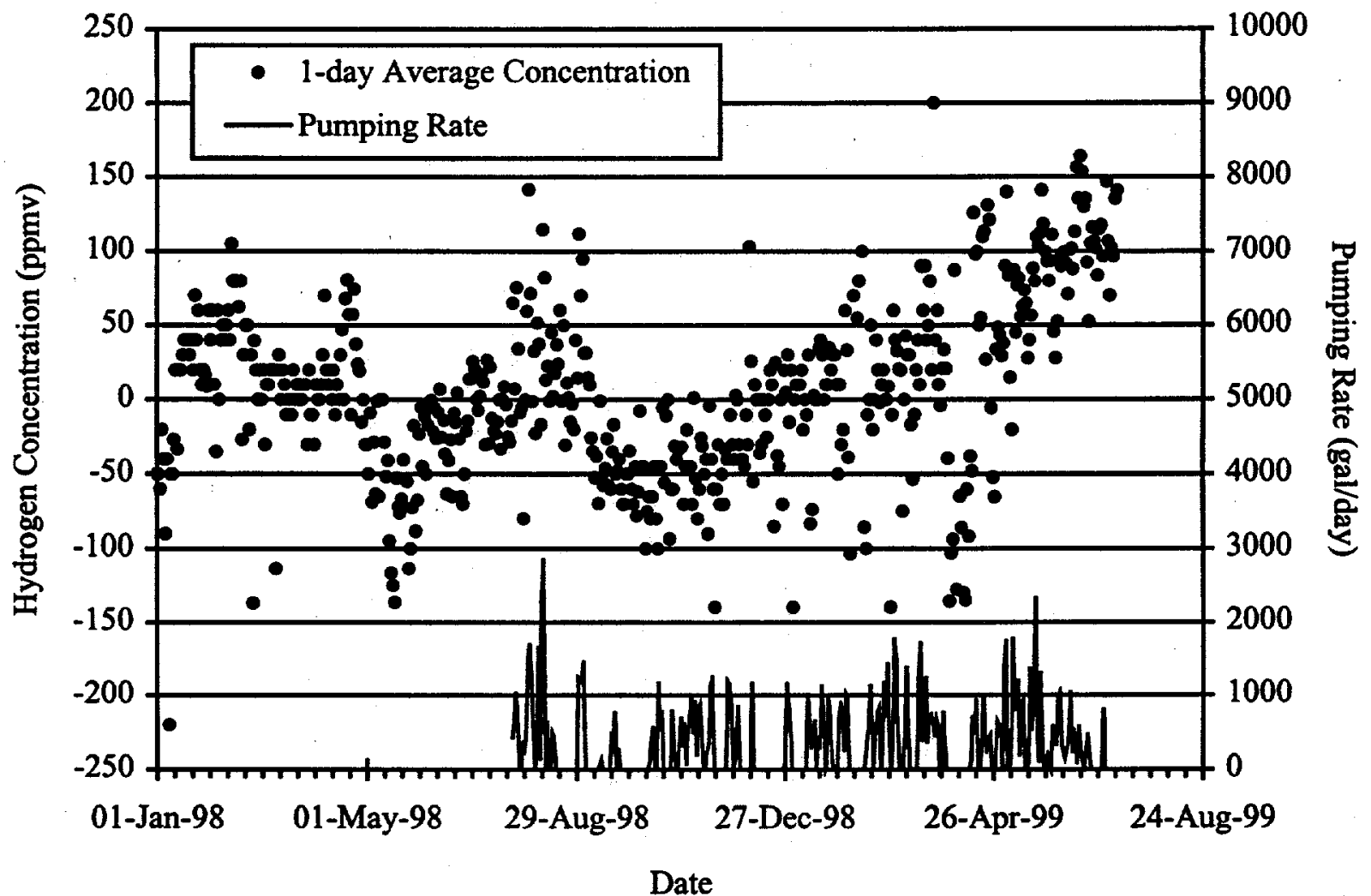

Figure 6.2 Tank SX-104 Headspace Hydrogen Concentration and Pumping Rate with Expanded Scale on Primary Y-axis and with Hydrogen Concentration Averaged over Each Day 


\subsection{Tank SX-106}

Tank SX-106 is another actively ventilated SST, and it is also on the FGWL. It is thought to retain somewhat more gas than tank SX-104 and is therefore in Facility Group 2. The void fraction was estimated by Hodgson et al. (1997) to be 0.09 , corresponding to a total initial gas inventory of $219 \mathrm{~m}^{3}\left(7,745 \mathrm{ft}^{3}\right)$. The ventilation rate is estimated to be about $3.3 \mathrm{~m}^{3} / \mathrm{min}(150$ $\mathrm{ft}^{3} / \mathrm{min}$ ) based on the total air flow of the SX-farm exhauster and the cascade position of tank SX$106^{(a)}$. The waste is $86 \%$ saltcake (Hanlon 1999). The tank was previously saltwell pumped in 1988 and 1989, at which time 428,500 L (113,200 gal) of liquid was removed (Stout et al. 1997). At the beginning of pumping, the tank was estimated to hold $2,037 \mathrm{~m}^{3}(538,000 \mathrm{gal})$ of waste, of which $1,317 \mathrm{~m}^{3}$ (348,000 gal) was pumpable liquid (Schreiber and Barker 1998).

A level rise in tank SX-106 of $46 \mathrm{~cm}$ (18 in.) has been observed since 1981 and attributed to accumulation of flammable gases. RGS samples were taken in 1997 and indicated a retained gas inventory of $360+/-180 \mathrm{~m}^{3(b)}$. The gas composition was measured to be $19 \%$ nitrogen, $47 \%$ hydrogen, $22 \%$ nitrous oxide, and $11 \%$ ammonia. Ammonia concentrations in the liquid phase were also unusually high, at up to $0.35 \mathrm{wt} \%$ (Field 1998).

Saltwell pumping of tank SX-106 began on October 7, 1998. As of July 25, 1999, about $351 \mathrm{~m}^{3}$ (92,700 gal) of waste had been pumped. As in tank SX-104, only headspace hydrogen concentration data from the SHMS Whittaker cell are available for this tank. Both tanks SX-104 and SX-105 are ventilated through tank SX-106, so the composition of the SX-106 headspace reflects releases from those tanks. At the estimated ventilation rate of $3.3 \mathrm{~m} / \mathrm{min}$, tank SX-106 would have to exhibit a sustained release of more than $40 \mathrm{ft}^{3} /$ day of hydrogen to raise its headspace concentration to 200 ppmv. Figure 7.1 shows the hydrogen concentration data and the daily pumping volumes. The large spikes are again due to instrument calibrations and do not represent gas releases. There is no discernible change in flammable gas level at the beginning of pumping in these data. Expanding the $y$-axis and calculating a daily average concentration, shown in Figure 7.2, reveals only a drop in the reading in January 1999 associated with a calibration event. No significant changes in flammable gas level are apparent.

(a) Letter report TWS99.42 from J Brothers (PNNL) to GD Johnson (LMHC), June 14, 1999, Draft Chapter 7 for Flammable Gas Topical Report.

(b) Mahoney LA, ZI Antoniak, and JM Bates. 1998. Preliminary Retained Gas Sampler Measurement Results for Hanford Waste Tank 241-SX-106. Letter Report TWS98.33, Pacific Northwest National Laboratory, Richland, Washington. 


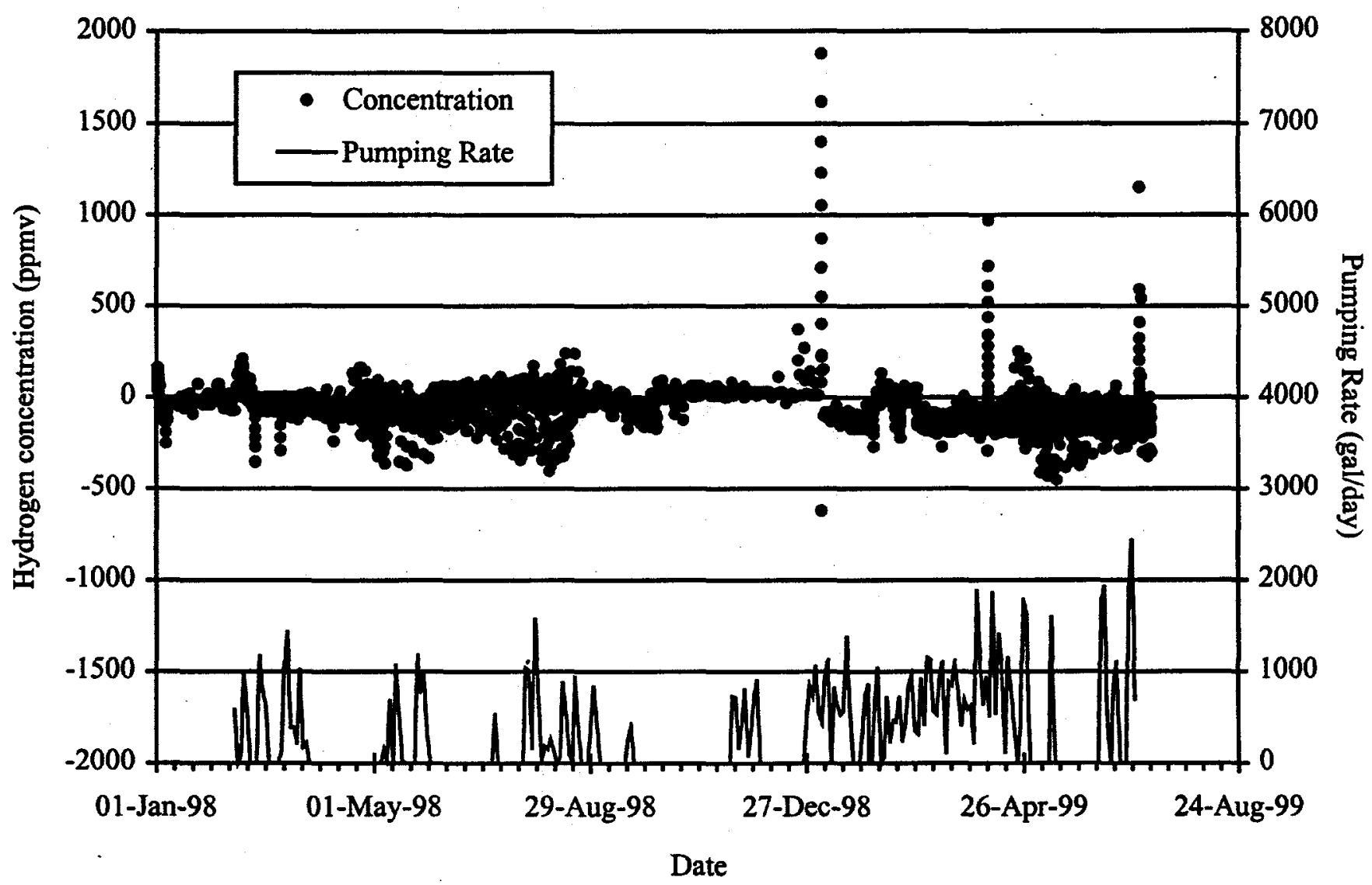

Figure 7.1 Tank SX-106 Headspace Hydrogen Concentration and Pumping Rate 


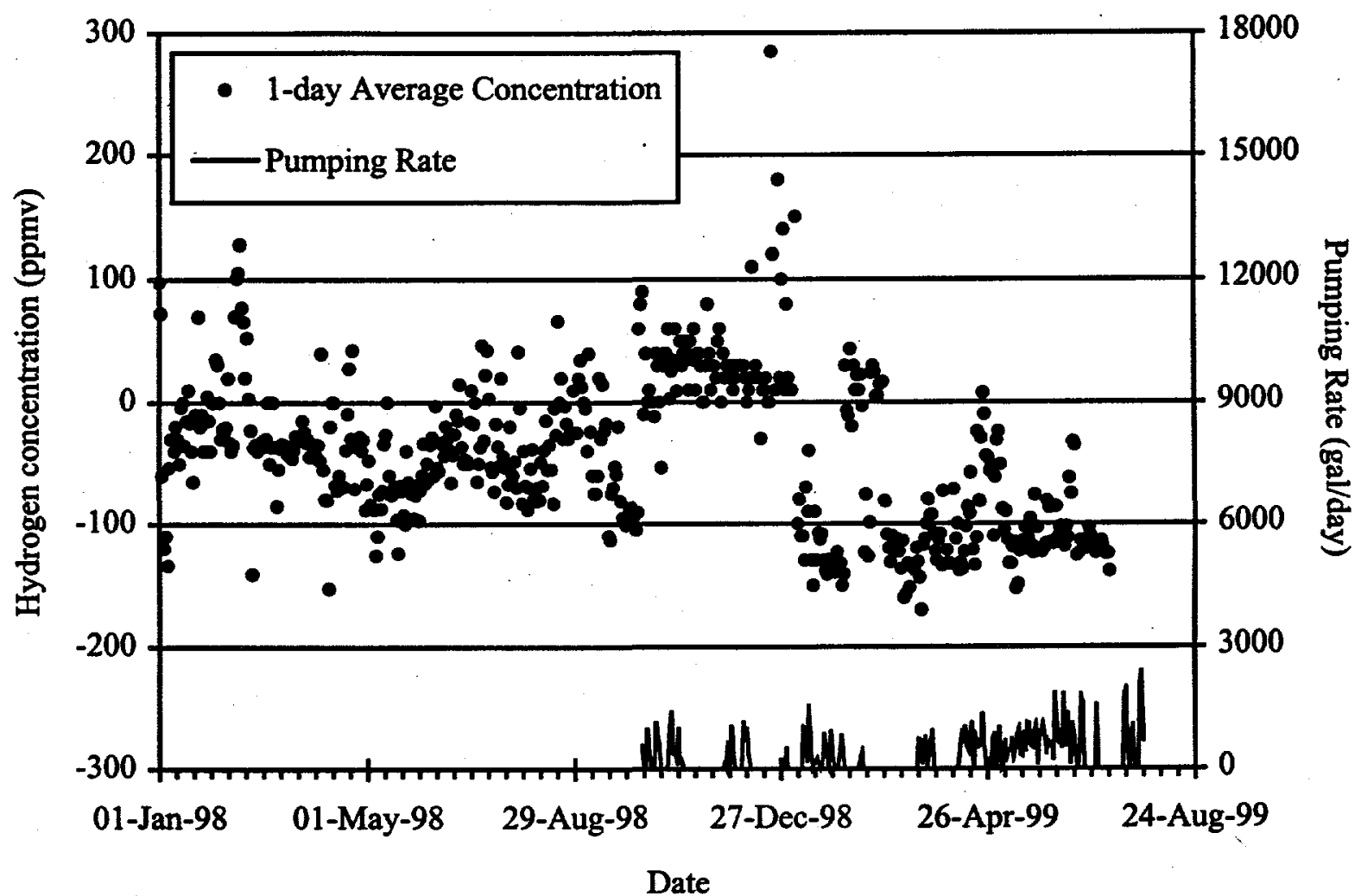

Figure 7.2 Tank SX-106 Headspace Hydrogen Concentration and Pumping Rate with Expanded Scale on Primary Y-axis and with Hydrogen Concentration Averaged over Each Day 


\subsection{Conclusions}

As expected, saltwell pumping of passively vented single-shell tanks with a significant flammable gas inventory (such as tanks S-106 and S-102) is resulting in elevated flammable gas concentrations in the headspaces of those tanks. To date, these concentrations have not approached lower flammability limits. Actively ventilated tanks (such as SX-104 and SX-106) have not shown elevated hydrogen concentrations. This is not surprising given the dilution introduced by ventilation air, the low sensitivity of the instrumentation used, and, in the case of tank SX-104, the small amount of flammable gas in the waste.

The apparent rates of gas release from both tanks S-106 and S-102 are lower than predicted by STOMP. In tank S-106, hydrogen and nitrous oxide are exhibiting a slow, prolonged release behavior that suggests that their diffusion out of the waste is hindered by mass transfer limitations. It is postulated that waste heterogeneities may be acting as barriers to diffusion by creating undrained regions in the waste.

Because release is slowed, turning off the pump does not cause the release rate to fall quickly, as previously expected. Moreover, due to the slowness of the release, it is not clear yet whether pumping will ultimately release all of the retained gas in tank S-106.

The ammonia release in tank S-106 is prolonged, which is expected. Disagreement between the magnitude of the observed release with the predicted release may be due to the presence of a region depleted in ammonia near the waste surface which absorbs ammonia released from below. If so, ammonia release rates should eventually be more in line with STOMP predictions.

Only hydrogen data are available for tank S-102, and pumping is only $10-20 \%$ complete. The hydrogen release rate is again much lower than expected. In this case, however, the gas that is released dissipates promptly in a manner consistent with unhindered gas phase diffusion through porous waste. A potential explanation for the discrepancy between the observed and predicted release volumes is that previous releases of gas have reduced the gas stored near the surface of the waste. However, this theory is at odds with RGS sampling data. Further pumping will provide more insight. 


\subsection{References}

Agnew SF. 1997. Hanford Tank Chemical and Radionuclide Inventories: HDW Model Rev. 4. LA-UR-96-3860, Los Alamos National Laboratory, Los Alamos, New Mexico.

Bredt PR and SM Tingey. 1996. The Effect of Dilution on the Gas Retention Behavior of Tank 241-SY-103 Waste. PNL-10893, Pacific Northwest National Laboratory, Richland, Washington.

Bredt PR, SM Tingey, and EH Shade. 1995. The Effect of Dilution on the Gas-Retention Behavior of Tank 241-SY-101 Waste. PNL-10781, Pacific Northwest Laboratory, Richland, Washington.

Brevick CH, JL Stroup, and JW Funk. 1997. Historical Tank Content Estimate for the Southwest Quadrant of the Hanford 200 West Area. HNF-SD-WM-ER-352, Rev. 1, Fluor Daniel Northwest Inc., Richland, Washington.

Carsel RF and RS Parrish. 1988. Developing Joint Probability Distributions of Soil Water Retention Characteristics. Water Resour. Res., Vol. 24, p.755-769.

U.S. District Court, Eastern District of Washington. 1999. Washington State Department of Ecology, plaintiff vs. U.S. Department of Energy, defendent.

Eggers RF. 1996. Tank Characterization Report for Single-Shell Tank 241-S-102. WHC-SDWM-ER-611, Rev. 0, Westinghouse Hanford Company, Richland, Washington.

Field JG. 1998. Tank Characterization Report for Single-Shell Tank 24I-SX-106. HNF-SDWM-ER-645, Rev. 1, Lockheed Martin Hanford Corp., Richland, Washington.

Field JG, SR Wilmarth, and GL Miller. 1998. Tank Characterization Report for Single-Shell Tank 241-S-106. HNF-SD-WM-ER-714, Rev. 1, Fluor Daniel Hanford, Inc., Richland, Washington.

Gauglitz PA, LA Mahoney, DP Mendoza, and MC Miller. 1994. Mechanisms of Gas Bubble Retention. PNL-10120, Pacific Northwest Laboratory, Richland, Washington.

Gauglitz PA, SD Rassat, MR Powell, RR Shah, and LA Mahoney. 1995. Gas Bubble Retention and its Effect on Waste Properties: Retention Mechanisms, Viscosity, and Tensile and Shear Strengths. PNL-10740, Pacific Northwest Laboratory, Richland, Washington. 
Gauglitz PA, SD Rassat, PR Bredt, JH Konynenbelt, SM Tingey, and DP Mendoza. 1996. Mechanisms of Gas Bubble Retention and Release: Results for Hanford Waste Tanks 241-S-102 and 241-SY-103 and Single-Shell Tank Simulants. PNNL-11298, Pacific Northwest National Laboratory, Richland, Washington.

Grimes GW. 1978. Jet Pump Development for Salt Well Application. RHO-CD-316, Rockwell Hanford Operations, Richland, Washington.

Hanlon BM. 1999. Waste Tank Summary Report for Month Ending November 30, 1998. HNFEP-0182-128, Fluor Daniel Hanford, Inc., Richland, Washington.

Herting DL, DB Bechtold, BA Crawford, TL Welsh, and L Jensen. 1992. Laboratory Characterization of Samples Taken in May 1991 from Hanford Waste Tank 241-SY-101. WHCSD-WM-DTR-024 Rev. 0., Westinghouse Hanford Company, Richland, Washington.

Hodgson KM, RP Anantatmula, SA Barker, KD Fowler, JD Hopkins, JA Lechelt, DA Reynolds, DC Hedengren, RE Stout, RT Winward, and JD Bingham. 1997. Evaluation of Hanford Tanks for Trapped Gas. WHC-SD-WM-ER-526, Rev. 1b, Lockheed Martin Hanford Company, Richland, Washington.

Hopkins JD. 1995. Methodology for Flammable Gas Evaluations. WHC-SD-WM-TI-724, Westinghouse Hanford Company, Richland, Washington.

Huckaby, JL, JC Evans, KB Olsen, KM Remund, and DS Sklarew. 1997a. Measurements of Waste Tank Passive Ventilation Rates Using Tracer Gases. PNNL-11683, Pacific Northwest National Laboratory, Richland, Washington.

Huckaby JL, JC Hayes, L Jensen, LL Buckley, RD Cromar, LD Pennington, and SR Wilmarth. 1997b. Homogeneity of Passively Ventilated Waste Tanks. PNNL-11640, Pacific Northwest National Laboratory, Richland, Washington.

Huckaby JL, DS Sklarew, JC Evans, and AV Mitroshkov. 1998. Waste Tank Ventilation Rates Measured with a Tracer Gas Method. PNNL-11925, Pacific Northwest National Laboratory, Richland, Washington.

Mahoney LA, ZI Antoniak, and JM Bates. 1997a. Composition and Quantities of Retained Gas Measured in Hanford Waste Tanks 241-U-103, S-106, BY-101, and BY-109. PNNL-11777, Pacific Northwest National Laboratory, Richland, Washington.

Mahoney LA, ZI Antoniak, JM Bates, and A Shekarriz. 1997b. Preliminary Retained Gas Sampler Measurement Results for Hanford Waste Tank 241-U-103. TWSFG97.40, Pacific Northwest National Laboratory, Richland, Washington. 
Meader WH. 1996. A Safety Assessment for Salt Well Jet Pumping Operations in Tank 241-A101: Hanford Site, Richland, Washington. WHC-SD-WM-SAD-036, Rev. 0, Westinghouse Hanford Company, Richland, Washington.

Noorani YG. 1997. Tank Waste Remediation System Basis for Interim Operation. HNF-SDWM-BIO-001, DE\&S Hanford, Inc., Richland, Washington.

Norton JD and LR Pederson. 1994. Ammonia in Simulated Hanford Double-Shell Tank Wastes: Solubility and Effects on Surface Tension. PNL-10173, Pacific Northwest National Laboratory, Richland, Washington.

Peurrung LM, SM Caley, EY Bian, and PA Gauglitz. 1996. Gas Release During Salt Well Pumping: Model Predictions and Comparisons to Laboratory Experiments. PNNL-11310, Pacific Northwest National Laboratory, Richland, Washington.

Peurrung LM, SM Caley, and PA Gauglitz. 1997. Gas Release During Salt-Well Pumping: Model Predictions and Laboratory Validation Studies for Soluble and Insoluble Gases. PNNL11621, Pacific Northwest National Laboratory, Richland, Washington.

Peurrung LM, LA Mahoney, CW Stewart, PA Gauglitz, LR Pederson, SA Bryan, and CL Shepard. 1998. Flammable Gas Issues in Double-Contained Receiver Tanks. PNNL-11836, Rev. 2, Pacific Northwest National Laboratory, Richland, Washington.

PNNL 1999. Tank Characterization Database. Version 3.24.

Rassat SD, and PA Gauglitz. 1995. Bubble Retention in Synthetic Sludge: Testing of Alternative Gas Retention Apparatus. PNL-10661, Pacific Northwest Laboratory, Richland, Washington.

Rassat SD, PA Gauglitz, PR Bredt, LA Mahoney, SV Forbes, and SM Tingey. 1997. Mechanisms of Gas Retention and Release: Experimental Results for Hanford Waste Tanks 241$A W-101$ and 241-AN-103. PNL-11642, Pacific Northwest Laboratory, Richland, Washington.

Rassat SD, SM Caley, PR Bredt, PA Gauglitz, DE Rinehart, and SV Forbes. 1998. Mechanisms of Gas Retention and Release: Experimental Results for Hanford Single-Shell Waste Tanks 241$A-101,241-S-106$, and 241-U-103. PNL-11981, Pacific Northwest Laboratory, Richland, Washington.

Reynolds DA. 1992. Tank 101-SY Window C Core Sample Results and Interpretation. WHCEP-0589, Westinghouse Hanford Company, Richland, Washington.

Schreiber, RDm and SA Barker. 1998. Updated Jet Pump Durations for Interim Stabilization of Remaining Single-Shell Tanks. HNF-2978 Rev. 0, Lockheed Martin Hanford Corporation, Richland, Washington. 
Schumpe A. 1993. The Estimation of Gas Solubilities in Salt Solutions. Chem. Eng. Sci. 48:153.

Simmons CS. 1996. Modeling Water Retention of Simulant Sludge and Actual Saltcake Tank Wastes. PNL-10831, Pacific Northwest Laboratory, Richland, Washington.

Spore JW. 1996. Conservative Gas Releases for Tank 241-A-101. Los Alamos National Laboratory Calc-Note, TSA10-CN-WT-SA-GR-046.

Stewart CW, ME Brewster, PA Gauglitz, LA Mahoney, PA Meyer, KP Recknagle, and HC Reid. 1996. Gas Retention and Release Behavior in Hanford Single-Shell Tanks. PNNL-11391, Pacific Northwest National Laboratory, Richland, Washington.

Stout RE, RT Winward, and MJ Kupfer. 1997. Preliminary Tank Characterization Report for Single-Shell Tank 241-SX-104: Best-Basis Inventory. HNF-SD-WM-ER-643, Rev. 0, Lockheed Martin Hanford Corporation, Richland, Washington.

van Genuchten MTh. 1980. "A Closed-Form Equation for Predicting the Hydraulic Conductivity of Unsaturated Soils." Soil Sci. Soc. Am. J.. 44: 892-898.

Vladimiroff DT, VC Boyles, WR Swita, MR Koch, JO Honeyman, JG Lewis, TM Horner, JR Kriskovich, CR Hutchins, JA Crawford, K Parnell, BD Zimmerman, MN Johnson, RP Raven, AD Basche, JA Morrison, DJ Saueressig, and AJ Diliberto. 1999. Single-Shell Tank Interim Stabilization Project Plan. HNF-2358, Rev. 3, Fluor Daniel Northwest, Inc., Richland, Washington.

Welty JR, CE Wicks, and RE Wilson. 1984. Fundamentals of Momentum, Heat, and Mass Transfer, 3rd Edition. John Wiley and Sons, New York.

White MD and M Oostrom. 1996. STOMP Subsurface Transport Over Multiple Phases, Theory Guide. PNNL-11217, Pacific Northwest National Laboratory, Richland, Washington.

White MD and M Oostrom. 1997. STOMP Subsurface Transport Over Multiple Phases, User's Guide. PNNL-11218, Pacific Northwest National Laboratory, Richland, Washington.

Whitney P. 1995. Screening the Hanford Tanks for Trapped Gas. PNL-10821, Pacific Northwest National Laboratory, Richland, Washington. 


\section{Distribution}

No. of

Copies

\section{Offsite}

2 Office of Scientific and Technical Informaiton

H. Babad

2540 Cordoba Ct.

Richland, WA 99352

C. W. Forsberg

Oak Ridge National Laboratory

P.O. Box 2008 MS 6495

Oak Ridge, TN 37831

B. C. Hudson

P.O. Box 271

Lindsborg, KA 67456

T. E. Larson

2711 Walnut St.

Los Alamos, NM 87544

3 Los Alamos National Laboratory

P.O. Box 1663

Los Alamos, NM 87545

Attn:

$\begin{array}{ll}\text { D. R. Bennett } & \text { K575 } \\ \text { W. Kubic } & \text { K575 } \\ \text { C. Unal } & \text { K575 }\end{array}$

J. L. Kovach

Nuclear Consulting Services, Inc.

P.O. Box 29151

Columbus, OH 43229-0151
No. of

Copies

D. A. Powers

Sandia National Laboratories

MS-0744

Albuquerque, NM 87185-0744

S. E. Slezak

Sandia National Laobratory

P.O. Box 5800 MS 1004

Albuquerque, NM 87110

A. Balero

Washington Department of Ecology

1315 W. $4^{\text {th }}$, B5-18

Kennewick, WA 99336

Onsite

3 DOE Richland Operations Office

K. Chen

A4-70

C. A. Groendyke

H6-60

G. W. Rosenwald

H6-60

17 PHMC Team

S. A. Barker

R2-11

W. B. Barton

R2-11

R. E. Bauer

S7-73

D. R. Bratzel

S7-73

R. J. Cash

S7-73

K. M. Hodgson

R2-11

G. D. Johnson (3)

S7-73

N. W. Kirch

R2-11

M. A. Lane

G3-12

J. W. Lentsch

R3-25

D. J. McCain

R2-11

D. A. Reynolds

R2-11

E. R. Siciliano

B4-43

L. M. Stock

S7-73

D. T. Vladimiroff 
No. of

Copies

$44 \quad$ Pacific Northwest National Laboratory

J. W. Brothers (5) K9-20

P. A. Gauglitz (10) P7-41

M. E. Hevland K2-20

J. L. Huckaby (10) K6-80

L. A. Mahoney K7-15

L. M. Peurrung (10) K6-24

C. W. Stewart K7-15

M. D. White K9-36

Information Release (5) K1-06

Distr.2 